\title{
Youth access to ICT resources and subjective well-being in the Middle East: A Spatial bivariate copula regression analysis
}

\author{
Ibrahim Niankara ${ }^{1 *}$, Ghaleb A. El-Refae ${ }^{2}$, Amer Qasim ${ }^{3}$ \\ ${ }^{1,2,3}$ College of Business, Al Ain University, P.O. Box: 112612, Abu Dhabi, UAE; Tel: +97124444696. \\ "Corresponding author Ext: 539; Fax: +97124444304; Email: Ibrahim.niankara@aau.ac.ae
}

\begin{abstract}
Target 9.c of the 2015 United Nations (UN) sustainable development goals (SDGs) specifically addresses increasing access to information and communication technology (ICT) resources, and striving for universal access to the internet by 2020. The present study seeks to evaluate the effectiveness of the youth related national strategies implemented in this regard by a select number of countries in the Middle East region. The study does so, by relying on a spatial bivariate copula regression analysis of data on youth respondents from five countries, extracted from the 2018 Program for international students' assessment (PISA).
\end{abstract}

Focusing specifically on evaluating the availability of ICT resources to the youth population, and also identifying the impact of ICT resources on youth subjective well-being in the region, we find that except for the UAE and Qatar that have above OECD average youth performance on the ICT resource index, youth from the remaining countries reported below OECD level average access to ICT resources. The within region cross-country comparative analysis of ICT resources availability to the youth population at home, also highlighted significant heterogeneity across the five countries, post 2015 SDG adoption by UN country members.

Furthermore, looking at the impact of ICT resources on youth well-being, controlling for not only cross-country spatial correlations, and factors such as home educational resources, cultural possessions at home, parental occupation status, youth expected occupation status, economic and socio-cultural status, age, gender, and grade level in school; we found that every standard deviation increase in ICT resources to the youth population in the region raises their selfexpressed sense of belonging in school by $1.88 \%$ standard deviations. Given the empowering nature of ICT resources to youth, and the potential of both to support national as well as regional economic development initiatives, a concerted effort to ease ICT resources diffusion by member countries in the middle east region could assist not only each country in its own development path, but also the region as a whole to live up to its growth potential by the 2030 .

Keywords: Copula Regression, ICT resources, Middle East, Spatial Analysis, Students Wellbeing, Sustainable Development Goals

\section{Introduction}

\subsection{Background:}

In 2015 as part of their 2030 Agenda, United Nation (UN) country members defined a set of development goals with specific targets for sustainability, known as the Sustainable 
Development Goals (SDGs) (United Nations, 2015). Together, the 17 goals address various dimensions of life including access to and usage of information and telecommunication technologies (ICT), which is covered by SDG goal 9, and target 9.c.

Indeed, while SDG goal 9 is generally concerned with building resilient infrastructure, promoting sustainable industrialization and fostering innovation, its target 9.c focuses specifically on significantly increasing access to information and communications technology and striving to provide universal and affordable access to the internet, especially in least developed countries by 2020. Today in the dawn of year 2020, and nearly five years into implementation of SDG strategies, key questions arise in relation to the effectiveness of the implemented SDG strategies to date. Among others, one may seek for example to understand:

(i) How successful are countries in moving towards achieving their ICT related goals?

(ii) How has advances in ICT related targets affected outcomes (key performance indicators) so far?

\subsection{Motivation}

The present study is therefore conducted with these two general questions in mind, but focusing specifically on the experience of the youth population in a select number of Middle Eastern countries, covered by the 2018 Program for International Students Assessment (PISA). The emphasis is on youth well-being ${ }^{1}$ in general, and Middle Eastern youth in particular, because youth are the bearer of the future being safeguarded by the 2030 SDGs, but also because youth in the Middle East have not received as much attention from the general research community, as their counterparts in the other world regions (Tiliouine \& Meziane, 2017).

In addition, the scientific evidence suggests that youth experiencing greater sense of holistic well-being are more able to learn and assimilate information in effective ways (Clement, 2010; Thapa et al., 2013; Wang \& Degol, 2016); more likely to engage in healthy and fulfilling social behaviors (Cohen, 2006; Poulou \& Norwich, 2019), and more likely to invest in their own and others' well-being and in the sustainability of the planet as they embrace their social, professional and leadership roles in adulthood (Blum, 2002; Scales et al., 2016).

Moreover, a review of the current scientific evidence on the availability, access, and usage consequences of ICT on various dimensions of youth life are split in their conclusions (Burr et al., 2019; Crompton et al., 2017; Dickson et al., 2019; Newland et al., 2018; Orben \& Przybylski, 2019; Parry et al., 2020; Vannucci \& Ohannessian, 2019; Xin et al., 2018). Two major trends seem to dominate however, those reporting adverse effects on youth psychological well-being (Dhir et al., 2019; Elhai et al., 2019; Marino et al., 2018; Sha et al., 2019; Sindermann et al., 2020), physical well-being (Domoff et al., 2019; Rodgers et al., 2020) and those reporting an overall positive effect of ICT use by the youth (Cangas, 2019; Goodall et al., 2013; James et al., 2017; Loebach et al., 2019; Loid et al., 2020).

\footnotetext{
${ }^{1}$ Defined as the realization of one's physical, emotional, mental, social and spiritual potential, well-being is regarded here as an optimal state of body, mind, emotions and spirit (Tomyn \& Cummins, 2011). It is about the desire and capacity to find meaning and hope within one's context, to make the most of what is, and to transform that which can be transformed, while contributing to one's own wellness as well as that of human and nonhuman environment as one evolves on one's life path. Developing youth well-being is thus about nurturing their capacity to grow and develop their gifts, to manage life's challenges, to care and be cared for, and to influence their surroundings in ways that enhance life for all.
} 


\subsection{Research Aim}

Given the unreconciled views, the present research aims primarily to look into the inner and subjective experiences that is, youth own views and experiences of their well-being (Ignatjeva et al., 2019; Kangas, 2010; Migliorini et al., 2019; Lau, 2019), which necessarily takes into account their perceptions of how such objective conditions as the home, school, society, ICT and media as learning environments affect their well-being (Tiliouine \& Meziane, 2017; Schütz et al., 2019; Zeng et al., 2016). Since the focus of promoting well-being in one community may be essentially different from what is required in another community (Navarro et al., 2019; Varela et al., 2019), the present study also seeks to address spatial heterogeneity in ICT availability and effects on youth well-being across nations in the Middle East. To this end, we rely on data from the 2018 PISA (OECD, 2019), covering five Middle Eastern countries, which are the United Arab Emirates (UAE), Qatar, Saudi Arabia, Jordan, and Turkey.

\subsection{Research Objectives:}

The specific objectives of the present study are twofold:

(i) To evaluate the availability and access to ICT resources by the youth population in the Middle East region post-2015 SDGs adoption

(ii) To identify the impact of ICT resources availability on youth subjective well-being in the region post-2015 SDGs adoption

In the pursuit of the above two objectives, the rest of the paper is organized as follows: Section 2 reviews briefly the literature on ICT and youth well-being to provide a conceptual framework for the analysis, section 3 describes the adopted methodology to bring the analysis to fruition, section 4 presents the results, which are further discussed in section 5, and finally section 6 concludes the analysis with policy recommendations, and future directions for research on the topic.

\section{Brief Literature Review and Conceptual Framework}

Although less so in the Middle East region (Tiliouine \& Meziane, 2017), the influence of ICT on youth well-being has received the attention of scholars in the recent past (Crompton et al., 2017; Newland et al., 2018; Loebach et al., 2019; Parry et al., 2020). Overall however, this effect is better understood within the context of the determinants of youth well-being, which can be categorized into internal (subjective) factors, and external (objective) factors (Strelhow et al., 2019). Because well-being as the realization of youth's physical, emotional, mental, social and spiritual potential is easily influenced by external circumstances and life events(Dinisman \& Ben-Arieh, 2016), much of the past research on youth well-being has tended to focus on the influence of external factors (Awartani, 2008). It is worth noting however that the experience of well-being is ultimately a subjective one and depends largely on each youth internal state of body, mind, emotions and spirit, which determines how (s)he engages with and responds to external circumstances.

Furthermore, within any given external environmental context, there exists a wide array of subjective experiences of well-being and ways in which people make meaning of the conditions in which they live (Moore \& Lynch, 2018). Therefore the dynamic balance, harmony and interplay among the internal and external factors condition the multidimensional aspects of youth well-being (Kern et al., 2015; Rose et al., 2017). Specifically, beyond the self, proven 
spheres of influence on youth well-being include economic conditions (Kaye-Tzadok et al., 2019 ; Saunders \& Brown, 2019; Main, 2019), the family (Dinisman et al., 2017; Thomson \& McLanahan, 2012), peers (Alcantara et al., 2017; Muscarà et al., 2018), school (Soutter et al., 2012 ; Miranda, 2019 ; Awartani, 2008; Poulou \& Norwich, 2019), ICT (Clayton et al., 2015) and media conditions in the community (Laurence, 2019; Lee \& Yoo, 2015), nation and region at large (Bradshaw et al., 2017). Taking into account the above discussion, and the various factors with proven influence on youth well-being, the following conceptual framework is proposed for our present research:

\section{ICT related Explanatory factors:}

- Link to the internet at home : "InternetLink"

- Number of phones with internet access at home: "nPhonInternAcH"

- Number of computers at home (desktop + laptop): "nCompH"

\section{Youth Personal characteristics}

- Age in years: "Age"

- Standardized Gender: "Gender"

- Grade level: "GradeLev"

- Expected occupation status: "ExpecOccup"

\section{Characteristics of youth home environment}

- Home educational resources: "HEDRES"

- Cultural possession at home: "CULTPOSS"

- Most spoken language at home: "LangH"

Youth family background characteristics

- international standard classification of highest parental education: "HISCED"

- Index of highest parental occupational status: "ESCS"

- Index of economic, social and cultural status: "HISEI"

\section{Stratification and weighting factors}

- Youth country of response: "CNT"

- Youth weight in the final sample: "W_FSTUWT"

Figure 1: Conceptual framework 


\section{Methodology}

\subsection{Data and Variables Description}

This paper relies on data from the student questionnaire file of the 2018 Program for International Student assessment (PISA) (OECD, 2019). PISA is the triennial survey of adolescent students around the world lunched by the Organization for Economic Co-operation and Development (OECD), to assess the extent to which students have acquired key competencies for full participation in modern societies. A detail description of the PISA sampling design is found in the OECD report (OECD, 2017, 67-91). Our analysis is based on the recently released 2018 student questionnaire data file, which includes among others information on ICT resource availability to the youth population, youth subjective well-being, socio-economic and demographic characteristics, the characteristics of their home and school environments, and family background. For the sake of keeping the discussions in this paper concise we keep the detailed description of the data in the supplementary materials. It is worth mentioning however that the pooled-cross sectional panel, covers youth respondents from 46 countries with a total sample size of 409747 observations. To meet the research objectives in the present study, we extracted the responses for all the youth from the five Middle Eastern countries shown in figure (2) below. This process yielded a 2018 cross-sectional sample of 37760 youth respondents, distributed across the United Arab Emirates (13409), Jordan (5996), Qatar (9212), Saudi Arabia (3324), and Turkey (5819). The conceptual framework in the previous section defines the select key variables used in the present analysis, while table (7) in the appendix provides their summary statistics.

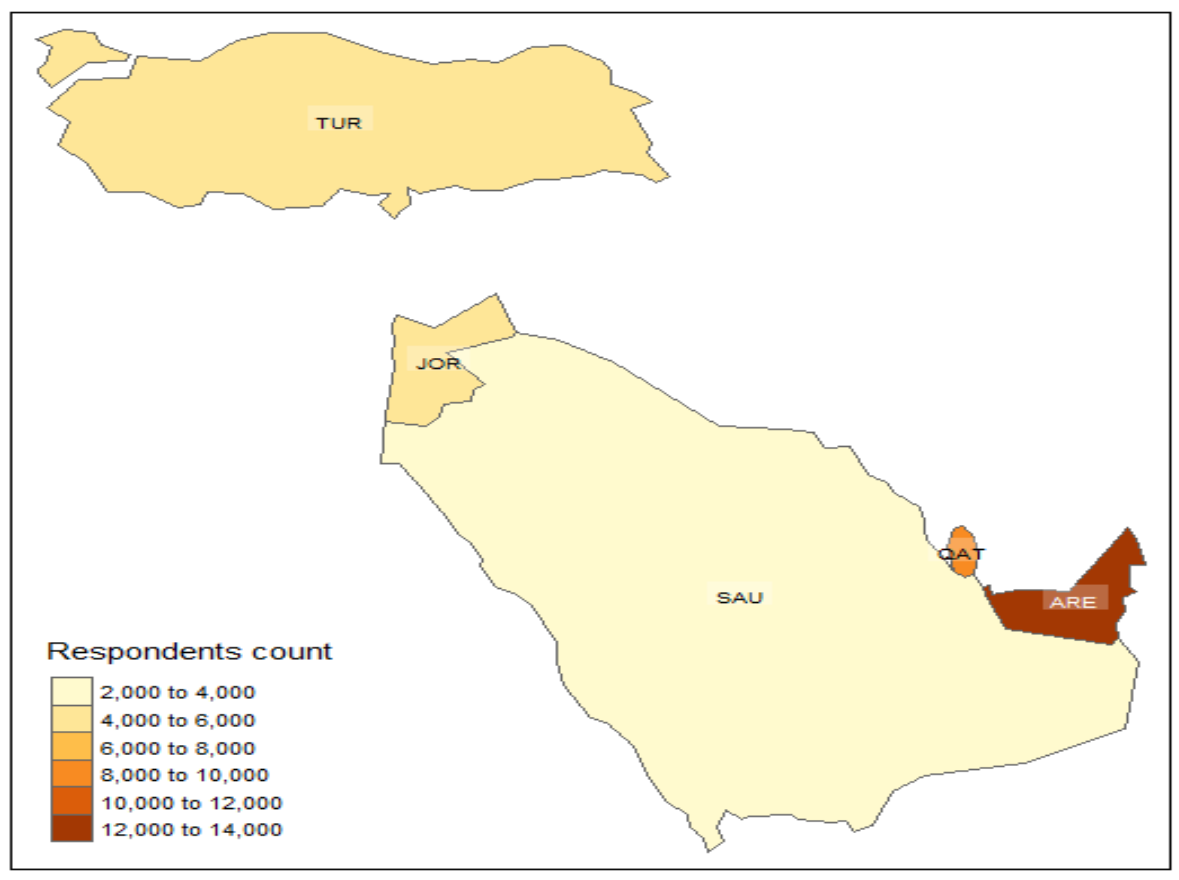

Figure 2: geographical map of respondents count by country

\subsubsection{Dependent variables}

The dependent variables in the present analysis are ICT resource availability to youth (ICTRES), and youth subjective well-being in terms of sense of belonging to school (BELONG). The two dependent variables are provided as indices in the 2018 PISA data. They are produced using weighted likelihood estimates (WLE; Warm, 1989) of youth respondents' 
scores on categorical items, which are transformed to an international metric with an OECD level mean of zero and an OECD level standard deviation of one. In this representation, youth with negative scores are those who responded less positively than the average student across OECD countries, while youth with positive scores are those who responded more positively than the average student in OECD countries. The use of standardized outcomes facilitates the cross-country comparisons in youth performances.

The first dependent variable (ICTRES) is explicitly derived for each youth respondent based on item response theory (IRT) scaling of two key factors (the availability of educational software resources, and a link to the internet at home). The second dependent variable (BELONG) as an indicator of youth subjective well-being is derived using six items, each scored on a four-point Likert scale, with the answering categories "strongly agree", "agree", "disagree", and "strongly disagree", and further described in table 16.16 of OECD (2017). For these two outcome variables higher weighted likelihood estimates (WLEs) correspond respectively to higher ICT resource availability and higher level of sense of belonging on all items. More elaborate descriptions of their construction can be retrieved from chapter 16 of the OECD technical report (OECD, 2017).

Figure (3) below provides the geographical maps of the country level weighted average values of ICTRES and BELONG across all youth respondents in the study sample. From the ICTRES index (left panel) it can be noted that youth from the UAE and Qatar score the highest, followed by those in Saudi Arabia, then Jordan and finally Turkey. On the other hand, the well-being index "BELONG" (right panel) shows youth from Saudi Arabia scoring the highest, followed by those in the UAE, then Jordan, with youth from Qatar and Turkey showing the lowest weighted average scores. In the next section we discuss the spatial bivariate normal copula additive framework, which is used to model the data, and then we proceed to describe its parameter identification and inference strategies.
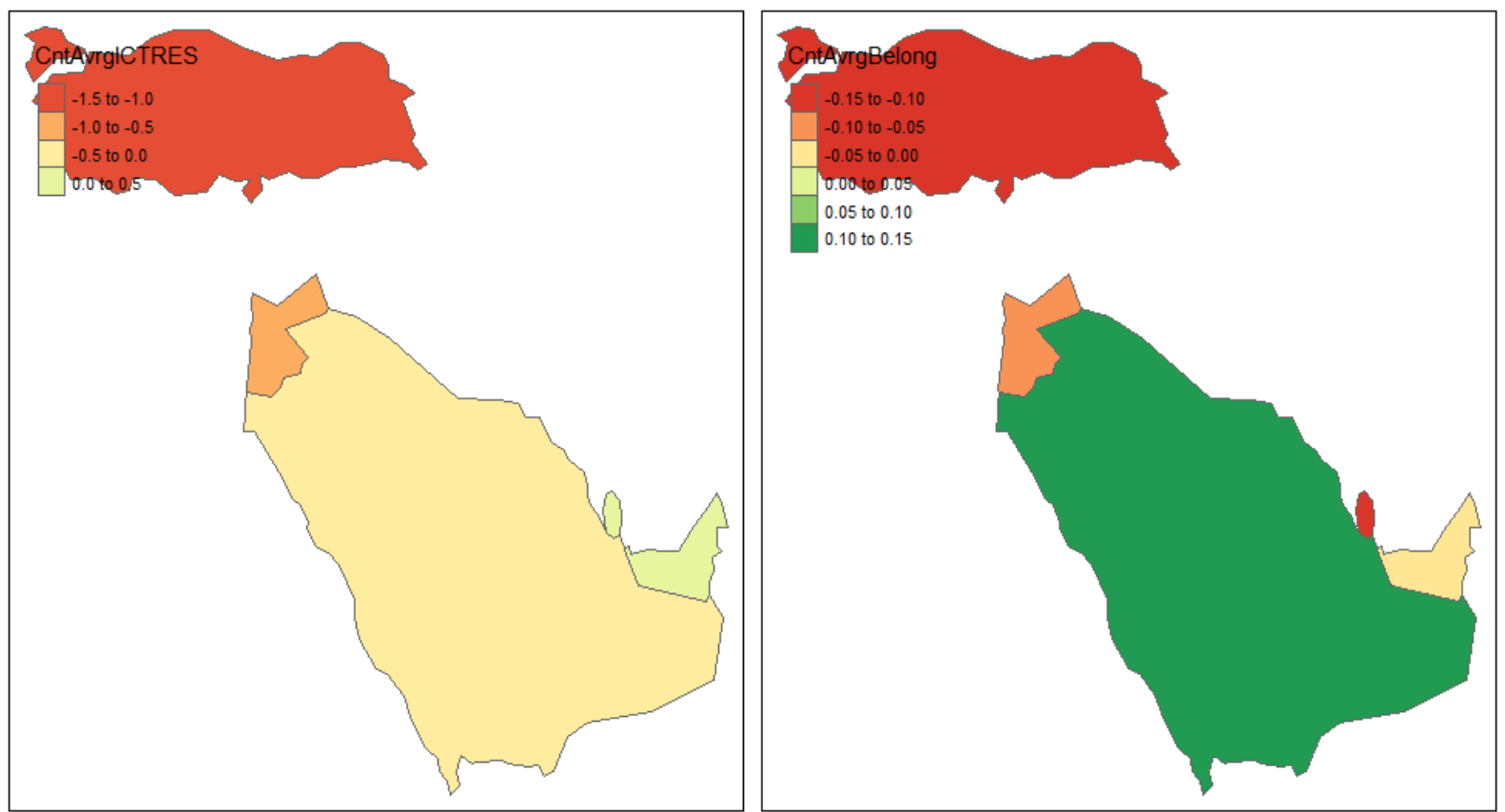

Figure 3: geographical maps of country level weighted average of standardized ICT resource availability (left panel) and youth subjective well-being (right panel) 


\subsection{Copula additive model for location, scale and shape}

The copula approach offers a convenient and computationally tractable framework to model multivariate responses in a regression context and has been the subject of many methodological developments over the last few years (e.g., Cherubini et al., 2004; Durante \& Sempi, 2010; De Leon \& Wu, 2011; Joe, 2014; Radice et al., 2016). The presented framework extends the copula models implemented in the VGAM R package (Yee, 2016) and represents a frequentist counterpart of the Bayesian approach by Klein \& Kneib (2015).

Let $Y_{1}$ be the amount of ICT resources available to youth, and $Y_{2}$ be youth subjective well-being in terms of self-expressed feeling of belonging in school. $Y_{1}$ and $Y_{2}$ are two continuous random variables with joint cumulative distribution function $F\left(y_{1}, y_{2} \mid z_{1}, z_{2}\right)$, where $z_{1}$ and $\boldsymbol{z}_{2}$ are the conditioning vectors of covariates explaining ICT resource availability and youth subjective well-being respectively with:

$$
\mathbf{z}_{1}=\left[\begin{array}{c}
\text { InternetLink, } \\
\text { nPhonInternAcH, } \\
\text { nCompH, } \\
\text { Age, } \\
\text { Gender, } \\
\text { GradeLev, } \\
\text { ExpecOccup, } \\
\text { HEDRES, } \\
\text { CULTPOSS, } \\
\text { LangH, } \\
\text { HISCED, } \\
\text { ESCS, } \\
\text { country }
\end{array}\right]^{T} \text { and } \mathbf{z}_{2}=\left[\begin{array}{c}
\text { nPhonInternAcH, } \\
\text { nCompH, } \\
\text { Age, } \\
\text { Gender, } \\
\text { GradeLev, } \\
\text { ExpecOccup, } \\
\text { HEDRES, } \\
\text { LangH, } \\
\text { HISCED, } \\
\text { HISEI } \\
\text { country }
\end{array}\right]^{T}
$$

Using Copula additive representation of the distribution function we have:

$$
F\left(y_{1}, y_{2} \mid z_{1}, z_{2}\right)=C\left(F_{1}\left(y_{1} \mid z_{1}\right), F_{2}\left(y_{2} \mid z_{2}\right) ; \theta\right)
$$

Where $F_{1}\left(y_{1} \mid z_{1}\right)$ and $F_{2}\left(y_{2} \mid z_{2}\right)$ are the marginal cumulative distribution functions of $Y_{1}$ and $Y_{2}$ and taking values between $(0,1) . C(.,$.$) is a uniquely defined two place copula function that$ does not depend on the individual marginal distribution functions, while $\theta$ is an association parameter for the copula function, and measuring the dependence between the two marginal distributions (Sklar, 1973 ; Kolev \& Paiva, 2009).

The marginal distributions of $Y_{1}$ and $Y_{2}$ are specified through parametric density functions that can be precisely denoted as: $F_{m}\left(y_{m} \mid \mu_{m}, \sigma_{m}, v_{m}\right)$ and $f_{m}\left(y_{m} \mid \mu_{m}, \sigma_{m}, v_{m}\right)$ for $m=1,2$, with $\mu_{m}, \sigma_{m}$ and $v_{m}$ representing the location, scale, and shape parameters of the marginal distributions (Stasinopoulos \& Rigby, 2007). Typically, the number of coefficients that characterize $F_{m}$ and $f_{m}$ depends on the assumed distribution for the copula function. For each copula function, Trivedi \& Zimmer (2007) show that there exists a relation between the correlation coefficient $\theta$ and the Kendall's $\tau$ coefficient, which is a convenient measure of association that lies in the customary range $[-1,1]$. 
For our present analysis, we assume a Gaussian copula described as $C(u, v ; \theta)=$ $\Phi_{2}\left(\Phi^{-1}(u), \Phi^{-1}(v) ; \theta\right)$ for $\theta \in[-1,1]$ with transformation function $\tanh ^{-1}(\theta)$, and Kendall's $\tau=\frac{2}{\pi} \arcsin (\theta)$.

\subsubsection{Predictors' Specification}

As shown in equation (1) the predictors $\boldsymbol{z}_{1}$ and $\boldsymbol{z}_{2}$ can be generically expressed as $\eta_{i t}$ across all youth $i$ in country $t$ in our study sample as:

$$
\eta_{i t}=\beta_{0 t}+\sum_{k=1}^{K} s_{k}\left(\mathbf{z}_{k i}\right), \forall i=1 \ldots n_{t} \text { and } t=1 \ldots 5
$$

Where $n_{t}$ represents the total number of youth respondents from country $t$ in the study sample, such that the total sample size across all countries is given by $\mathrm{N}=\sum_{t=1}^{5} n_{t}$. Similarly, $\beta_{0 t} \in \mathbb{R}$ is the country specific intercept, $\boldsymbol{z}_{k i}$ denotes the $k^{t h}$ sub-vector of the complete covariate vector $\boldsymbol{z}_{i}$, which contains binary, categorical, continuous, and spatial variables as described in equation (1) and the conceptual framework. The $K$ functions $s_{k}\left(\boldsymbol{z}_{k i}\right)$ represent generic effects which are chosen according to the type of covariate(s) under consideration. Each $s_{k}\left(z_{k i}\right)$ can be approximated as a linear combination of $J_{k}$ basis functions $b_{k J_{k}}\left(\mathbf{z}_{k i}\right)$ and regression coefficients $\beta_{k J_{k}} \in \mathbb{R}$, that is:

$$
\sum_{j_{k}=1}^{J_{k}} \beta_{k J_{k}} b_{k J_{k}}\left(\mathbf{z}_{k i}\right)
$$

In this form, Equation (4) implies that the vector of evaluations $\left\{s_{k}\left(\boldsymbol{z}_{k i}\right), \ldots, s_{k}\left(\boldsymbol{z}_{k n}\right)\right\}^{T}$ can be written as $\boldsymbol{Z}_{k} \boldsymbol{\beta}_{k}$ with $\boldsymbol{\beta}_{k}=\left(\beta_{k 1}, \ldots, \beta_{k}\right)^{T}$ with design matrix $Z_{k}\left[i, J_{k}\right]=b_{k J_{k}}\left(\boldsymbol{z}_{k i}\right)$. This allows the predictor in equation (3) to be written as:

$$
\boldsymbol{\eta}=\beta_{0} \mathbf{1}_{N}+\boldsymbol{Z}_{1} \boldsymbol{\beta}_{1}+\cdots+\boldsymbol{Z}_{k} \boldsymbol{\beta}_{k}
$$

Where $\mathbf{1}_{N}$ is an $\mathrm{N}=\sum_{t=1}^{5} n_{t}$ dimensional vector of ones. In a more compact notation, equation (5) can be rewritten as $\boldsymbol{\eta}=\boldsymbol{Z} \boldsymbol{\beta}$, with $\boldsymbol{Z}=\left(\mathbf{1}_{N}, \boldsymbol{Z}_{1}+\cdots+\boldsymbol{Z}_{k}\right)$ and

$\boldsymbol{\beta}=\left(\beta_{0}, \beta_{1}^{T}, \ldots, \beta_{K}^{T}\right)^{T}$. In this representation, the smooth functions may represent linear, nonlinear; random and spatial effects. Moreover, each $\beta_{k}$ has an associated quadratic penalty $\lambda_{k} \beta_{K}^{T} \boldsymbol{D}_{k} \beta_{k}$, which plays the role of enforcing specific properties on the $k^{\text {th }}$ function, such as smoothness. Smoothing parameter $\lambda_{k} \in[0, \infty)$ controls the trade-off between fit and smoothness, and play the role of determining the shape of $\hat{S}_{k}\left(\boldsymbol{z}_{k i}\right)$. The overall penalty can be defined as $\beta^{T} \boldsymbol{D}_{k} \beta$, with $\boldsymbol{D}_{k}=\operatorname{diag}\left(0, \lambda_{1} \boldsymbol{D}_{1}, \ldots, \lambda_{K} \boldsymbol{D}_{K}\right)$. For identification purposes, the smooth functions are mean centered following the procedure in wood (2017).

For variables with linear parametric effects, equation (4) becomes $\boldsymbol{Z}_{k i}^{T} \boldsymbol{\beta}_{k}$, and the design matrix is obtained by stacking all covariate vectors $\boldsymbol{Z}_{k i}$ into $\boldsymbol{Z}_{k}$. For continuous variables however, $Z_{k i}, s_{k}\left(Z_{k i}\right)$ is approximated by $\sum_{j_{k}=1}^{J_{k}} \beta_{k J_{k}} b_{k J_{k}}\left(Z_{k i}\right)$, where the $b_{k J_{k}}\left(Z_{k i}\right)$ are known spline basis. The smooth functions are represented using the regression spline approach presented by Eilers \& Marx (1996), with the design matrix $\boldsymbol{Z}_{k}$ comprising the basis function evaluations for each youth respondent $i$, and hence describing $J_{k}$ curves which have potentially varying degrees of complexity.

To incorporate the spatial effects into the copula regression, the five Middle Eastern countries covered in the study are split into discrete contiguous geographic units, with spatial coordinates exploited through a Markov random field approach. This latter approach is 
employed to exploit the information contained in neighboring youth respondents located in the same country. In this case, equation (4) becomes $\boldsymbol{Z}_{k i}^{T} \boldsymbol{\beta}_{k}$, with $\boldsymbol{\beta}_{k}=\left(\beta_{k 1}, \ldots, \beta_{K R}\right)^{T}$ representing the vector of spatial effects, $R=5$ denoting the total number of countries and $\boldsymbol{z}_{k i}$ made up of country labels. The design matrix linking each youth respondent $i$ to the corresponding spatial effect is defined for $r=1, \ldots 5$ by:

$$
Z_{k}[i, r]= \begin{cases}1 & \text { if the youth responent } i \text { belongs to country } r \\ 0 & \text { Otherwise }\end{cases}
$$

The smoothing penalty is based on the neighborhood structure of the discrete contiguous geographic units, so that youth from spatially adjacent countries share similar effects. Specifically the diagonal matrix associated with the quadratic penalty is given by:

$$
\boldsymbol{D}_{k}[r, q]=\left\{\begin{array}{l}
-1 \text { if } r \neq q \wedge r \approx q \\
0 \text { if } r \neq q \wedge r \neq q \\
N_{r} \text { if } r=q
\end{array}\right.
$$

Where $r \approx q$ indicates whether any two countries $r$ and $q$ are adjacent neighbors, and $N_{r}$ is the total number of neighbors for country $r$. The resulting quadratic penalty is equivalent to Rue \& Held (2005) stochastic interpretation that $\boldsymbol{\beta}_{k}$ follows a Gaussian Markov random field.

\subsubsection{Estimation Details}

For notational convenience, the density function of the copula function in equation (2) can be expressed for the overall parameter vector $\boldsymbol{\delta}=\left(\beta_{\mu_{1}}^{\boldsymbol{T}}, \beta_{\mu_{2}}^{\boldsymbol{T}}, \beta_{\sigma_{1}}^{\boldsymbol{T}}, \beta_{\sigma_{2}}^{\boldsymbol{T}}, \beta_{v_{1}}^{\boldsymbol{T}}, \beta_{v_{2}}^{\boldsymbol{T}}, \beta_{\theta}^{\boldsymbol{T}}\right)^{\boldsymbol{T}}$ as:

$$
\begin{aligned}
& f\left(y_{1 i}, y_{2 i} \mid \boldsymbol{\delta}\right) \\
& =c\left(F_{1}\left(y_{1 i} \mid \mu_{1 i} \sigma_{1 i} v_{1 i}\right), F_{2}\left(y_{2 i} \mid \mu_{2 i} \sigma_{2 i} v_{2 i}\right) ; \theta_{i}\right) f_{1}\left(y_{1 i} \mid \mu_{1 i} \sigma_{1 i} v_{1 i}\right) f_{2}\left(y_{2 i} \mid \mu_{2 i} \sigma_{2 i} v_{2 i}\right) ;
\end{aligned}
$$

With corresponding log-likelihood function following (Vatter \& Chavez-Demoulin, 2015), expressed as:

$$
\begin{gathered}
\ell(\boldsymbol{\delta})=\sum_{i=\mathbf{1}}^{N} \log \left\{c\left(F_{1}\left(y_{1 i} \mid \mu_{1 i} \sigma_{1 i} v_{1 i}\right), F_{2}\left(y_{2 i} \mid \mu_{2 i} \sigma_{2 i} v_{2 i}\right) ; \theta_{i}\right)\right\} \\
+\sum_{i=\mathbf{1}}^{N} \sum_{m=\mathbf{1}}^{2} \log \left\{f_{m}\left(y_{m i} \mid \mu_{m i} \sigma_{m i} v_{m i}\right)\right\}
\end{gathered}
$$

Using maximum penalized likelihood to identify the parameters of the model we maximize:

$$
\ell_{p}(\boldsymbol{\delta})=\ell(\boldsymbol{\delta})-\frac{1}{2} \boldsymbol{\delta}^{T} S_{\lambda} \boldsymbol{\delta}
$$

With $\boldsymbol{S}_{\lambda}=\operatorname{diag}\left(\boldsymbol{\lambda}_{\mu_{1}} \boldsymbol{D}_{\mu_{1}}, \boldsymbol{\lambda}_{\mu_{2}} \boldsymbol{D}_{\mu_{2}}, \boldsymbol{\lambda}_{\sigma_{1}} \boldsymbol{D}_{\sigma_{1}}, \boldsymbol{\lambda}_{\sigma_{2}} \boldsymbol{D}_{\sigma_{2}}, \boldsymbol{\lambda}_{v_{1}} \boldsymbol{D}_{v_{1}}, \boldsymbol{\lambda}_{v_{2}} \boldsymbol{D}_{v_{2}}, \boldsymbol{\lambda}_{\theta} \boldsymbol{D}_{\theta}\right)$ and each generic $\lambda$ defined as $\left(\lambda_{1}, \ldots, \lambda_{K}\right)^{T}$. Maximization of the above penalized maximum likelihood in equation (10) is achieved using the trust region algorithm introduced by Radice et al. (2016), along with the analytical score and Hessian Matrix of $\ell(\boldsymbol{\delta})$, which is defined by: 


$$
\begin{aligned}
& \frac{\partial \ell(\boldsymbol{\delta})}{\partial \boldsymbol{\beta}_{\mu_{1}}}=\sum_{i=1}^{N}\left\{\frac{1}{f_{1}\left(y_{1 i} \mid \mu_{1 i} \sigma_{1 i} v_{1 i}\right)} \frac{\partial f_{1}\left(y_{1 i} \mid \mu_{1 i} \sigma_{1 i} v_{1 i}\right)}{\partial \mu_{1 i}}+\right. \\
& \frac{1}{c\left(F_{1}\left(y_{1 i} \mid \mu_{1 i} \sigma_{1 i} v_{1 i}\right), F_{2}\left(y_{2 i} \mid \mu_{2 i} \sigma_{2 i} v_{2 i}\right) ; \theta_{i}\right)} \times \\
& \left.\frac{\partial c\left(F_{1}\left(y_{1 i} \mid \mu_{1 i} \sigma_{1 i} v_{1 i}\right), F_{2}\left(y_{2 i} \mid \mu_{2 i} \sigma_{2 i} v_{2 i}\right) ; \theta_{i}\right)}{\partial F_{1}\left(y_{1 i} \mid \mu_{1 i} \sigma_{1 i} v_{1 i}\right)} \frac{\partial F_{1}\left(y_{1 i} \mid \mu_{1 i} \sigma_{1 i} v_{1 i}\right)}{\partial \mu_{1 i}}\right\} \frac{\partial \mu_{1 i}}{\partial \eta_{1 i}} Z_{\mu_{1 i}}
\end{aligned}
$$

And similarly for the first order conditions of $\ell(\boldsymbol{\delta})$ with respect to $\beta_{\mu_{2}}, \beta_{\sigma_{1}}, \beta_{\sigma_{2}}, \beta_{v_{1}}$ and $\beta_{v_{1}}$, which present the same structures as the in equation (11); while

$$
\begin{aligned}
\frac{\partial \ell(\boldsymbol{\delta})}{\partial \boldsymbol{\beta}_{\theta}}=\sum_{i=1}^{N}\{ & \frac{1}{c\left(F_{1}\left(y_{1 i} \mid \mu_{1 i} \sigma_{1 i} v_{1 i}\right), F_{2}\left(y_{2 i} \mid \mu_{2 i} \sigma_{2 i} v_{2 i}\right) ; \theta_{i}\right)} \\
& \left.\times \frac{\partial c\left(F_{1}\left(y_{1 i} \mid \mu_{1 i} \sigma_{1 i} v_{1 i}\right), F_{2}\left(y_{2 i} \mid \mu_{2 i} \sigma_{2 i} v_{2 i}\right) ; \theta_{i}\right)}{\partial \theta_{i}} \frac{\partial \theta_{i}}{\partial \eta_{\theta_{i}}}\right\} \boldsymbol{Z}_{\theta_{i}}
\end{aligned}
$$

The score vectors and Hessian matrices for the Gaussian copula functions used in this analysis have been verified using the tools provided in the R library numDeriv (Gilbert \& Varadhan, 2016). At convergence of the implemented trust region algorithm (Radice et al. , 2016), reliable estimates of model coefficients are obtained using $\boldsymbol{\delta} \sim \mathcal{N}\left(\widehat{\boldsymbol{\delta}},-\widehat{\mathcal{H}}_{p}^{-1}\right)$ where $\mathcal{H}_{p}$ is the penalized Hessian Matrix. For further details, please refer to Wojtys \& Marra (2018).

\subsection{Model Implementation}

We implement the above described copula framework in the $\mathrm{R}$ statistical package using the "copulaReg()" function from the library "SemiParBIVProbit" (Marra \& Radice, 2017). More specifically, we consider the two response variables: ICT resources availability to youth (ICTRES), and youth subjective well-being (BELONG), along with the conditioning covariates $\left(z_{1}\right.$ and $\left.z_{2}\right)$ as expressed in equation (1), and further defined in the conceptual framework. The spatial bivariate copula regression model for the joint analysis of ICTRES and BELONG is appealing because of its flexibility for joint modelling and marginal inferences.

We first analyzed the unconditional marginal distributions of the two response variables. The normal Q-Q plots of the normalized quantile residuals as shown in figure (4) below suggest that the Gaussian copula is a good fit for both variables. We then proceeded to fit the spatial bivariate copula regression model following the guidelines described in section (3.2) above. The output of the fitted model was then used to compute the joint and independent cumulative probability density functions that a youth performs below the sample averages of ICTRES and BELONG. These averages are respectively $9.4 \%$ standard deviation, and $7.06 \%$ standard deviation below their OECD level counterparts. The results are summarized in figure (5), with the left panel assuming the two dependent variables are jointly defined [pr.jointC (in \%)], while the right panel assumes the two dependent variables are independently defined [pr.indepC (in \%)]. The $\mathrm{R}$ based computer codes for all analyses are provided in Appendix and supplementary materials. 

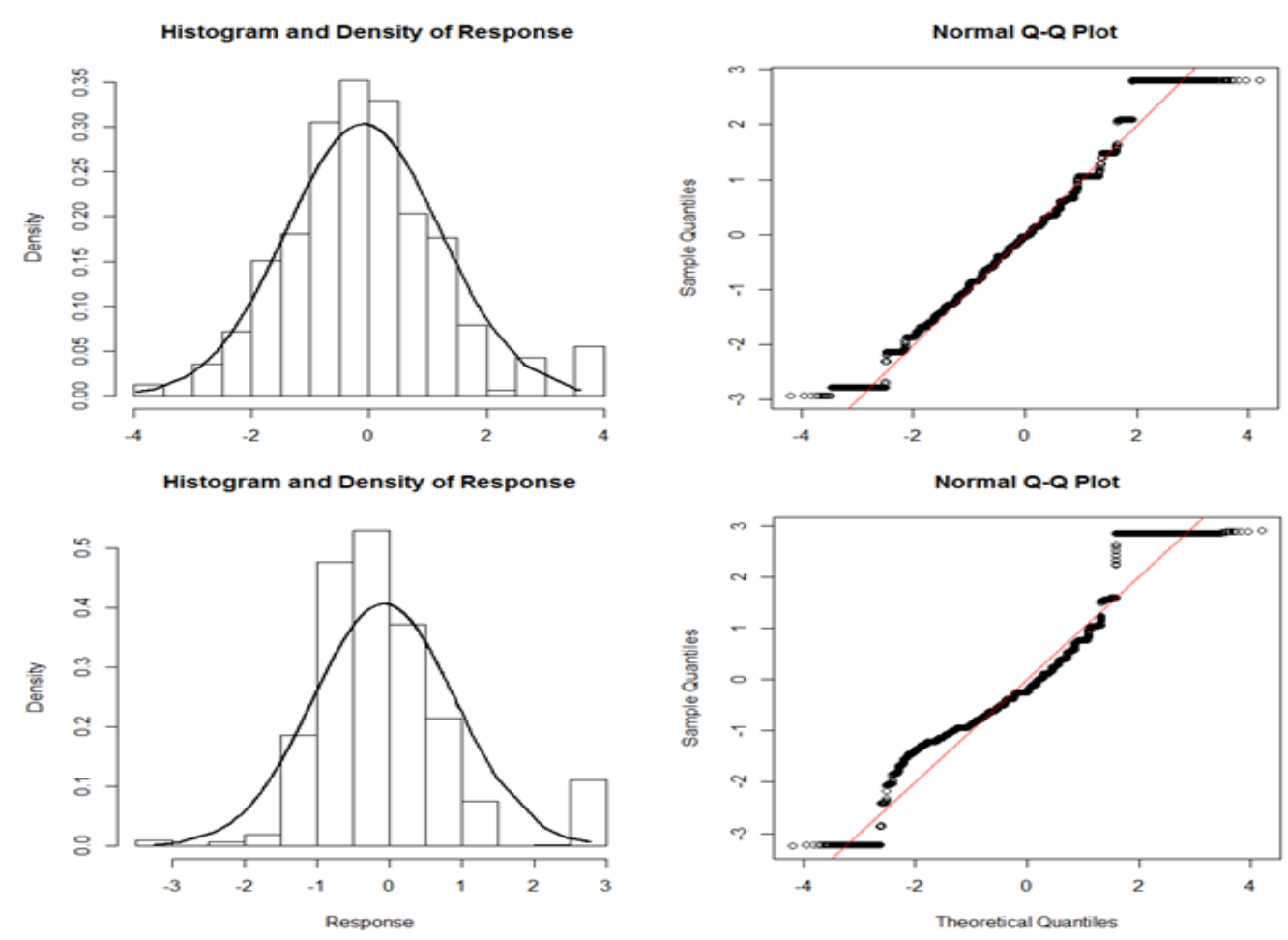

Figure 4: Histogram and normal Q-Q plots of the normalized quantile residuals of standardized ICT resource availability (top panel) and subjective well-being (lower panel)
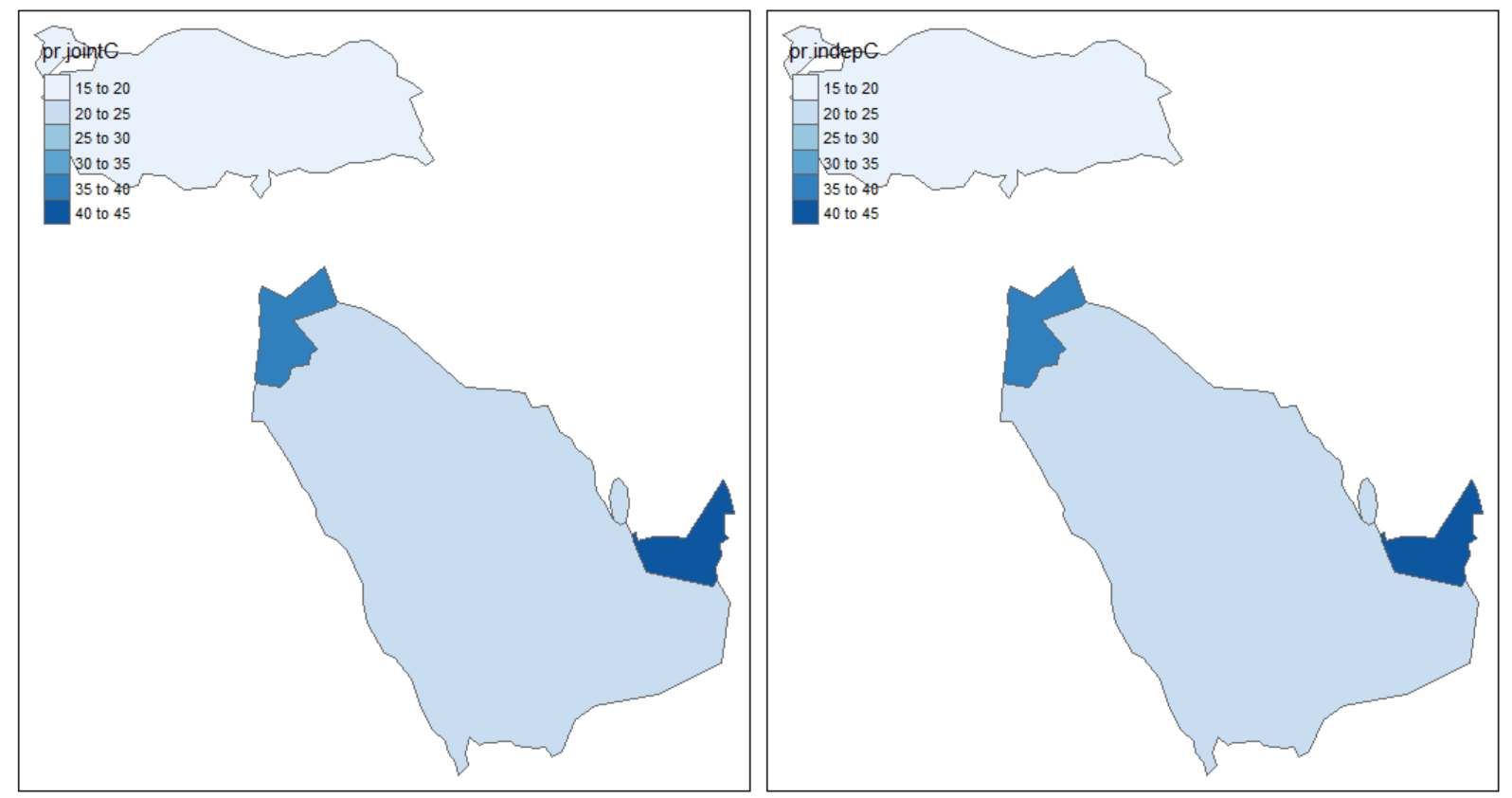

Figure 5: spatial distribution of the joint probabilities (in \%) that the dependent variables ICTRES and BELONG are both less than their standardized mean values of (-0.09486) and (-0.07064) respectively in the study sample. These have been calculated using the spatial bivariate Gaussian copula model. The independence model (right panel) assumes that the two variables are not associated after controlling for covariates effects. 


\section{Results}

The result section is broadly organized into three subsections presenting respectively (i) descriptive findings from the quantitative variables (mean, standard deviation), and qualitative variables (absolute frequency and percent relative frequencies of levels); (ii) paired hypothesis tests results of difference in national level youth weighted average performances on key indexes including the ICT resource index and the subjective well-being index; and finally (iii) the econometric results from the fitted spatial bivariate copula regression model of youth access to ICT resources and subjective well-being in the Middle East, post 2015 SDG adoption.

\subsection{Descriptive Findings}

The means, standard deviations, absolute frequencies and percent relative frequencies of the quantitative and qualitative variables in the study are shown in table (7) in the appendix. From table (7) it can be noted that out of 37760 youth respondents in the study sample, $35.51 \%$ are responding from the UAE, 15.88\% from Jordan, 24.40\% from Qatar, 8.80\% from Saudi Arabia, and finally $15.41 \%$ from Turkey. The greater majority of which $(60.81 \%)$ are natives of their country of testing, $25.03 \%$ are first generation immigrant/expatriates, and $14.16 \%$ are second generation expatriates. Most of them (73.19\%) speak mostly the language of the PISA test at home, with only a few (26.81\%) reporting speaking mostly another language. In addition, an overwhelming $91.64 \%$ reports having a link to the internet at home, against only $8.36 \%$ reporting not. On the basis of gender, $54.75 \%$ of the respondents are females, while the remaining $45.25 \%$ are males. The greater majority of the youth respondents $(69.13 \%)$ are in $10^{\text {th }}$ grade, followed by $14.92 \%$ in $11^{\text {th }}$ grade, then by $13.21 \%$ in $9^{\text {th }}$ grade, and the remaining distributed across $8^{\text {th }}$ grade $(1.73 \%), 12^{\text {th }}$ grade $(0.71 \%)$, and $7^{\text {th }}$ grade $(0.30 \%)$ respectively.

The summary statistics of the dependent variables suggest that the average youth respondent in the study sample, reports a subjective well-being index value $7.1 \%$ standard deviation below the OECD average; while also scoring 9.5\% standard deviation below OECD average on the ICT resource index. For the remaining quantitative predictors, it can be noted that the average youth respondent in the sample is about 15.80 years young, and reports more than three phones with internet access at home, and the presence of more than two computers including desktop, laptop, and notebook at home. The indexes of home educational resources, and cultural possessions at home are also seen to be $37.45 \%$ and $55.7 \%$ standard deviation below their OECD level counterparts. Finally table (7) also shows that youth respondents in the sample score $13.6 \%$ below the OECD average index value for economic, social and cultural status.

\subsection{Cross-country pair-wise t-test results of weighted mean differences}

Using the original youth level response data across the five countries as initially described in the data section above, we aggregated the data to obtain country level averages of the two response variables "ICTRES" and "BELONG", along with key quantitative variables such as: the Index of home educational resources (HEDRES), the index of Economic and Socio-cultural Status (ESCS), and the Wealth index (WEALTH). Aggregation was achieved using the "group_by" function in the "dplyr" library within the R statistical package, to group the data by country. Since the original youth level data contains a unique probability weight for each youth respondent in the sample, we incorporated the weights to calculate weighted means and weighted standard deviations for each of the above referenced variables using functions form the "SBMTools" library in R. In doing so, we were able to produce country level aggregated 
data (CNToutcDatat), which were representative of the general youth population in each of the five countries. This R data object "CNToutcDatat" was then transposed, and saved into coma separated variable (.csv) format, for the pair-wise hypothesis tests of difference in means across the five countries. The tests were carried out using the Excel add-in "MegaStat". The results of these tests are presented in the tables ( 2 to 6 ) below. We also used the (.csv) formatted data to represent graphically the distributions of weighted means and standard deviations of the five variables mentioned above. Figures (6 to 10) summarize these plots.

Table 1: Mean, standard deviation and sample size of the aggregated indices across the five countries.

\begin{tabular}{|c|c|c|c|c|c|c|}
\hline & & BELONG & ICTRES & HEDRES & ESCS & WEALTH \\
\hline \multirow[t]{3}{*}{ UAE } & Mean: & -0.0457 & 0.4316 & -0.0060 & 0.3369 & 0.5379 \\
\hline & SD: & 0.9870 & 1.2231 & 1.0788 & 0.8298 & 1.3187 \\
\hline & $\mathrm{N}$ & 13409 & 13409 & 13409 & 13409 & 13409 \\
\hline \multirow[t]{3}{*}{ JOR } & Mean: & -0.0997 & -0.8712 & -0.8348 & -0.5896 & -0.9604 \\
\hline & SD: & 0.9495 & 1.1067 & 1.2491 & 1.0773 & 1.1563 \\
\hline & $\mathrm{N}$ & 5996 & 5996 & 5996 & 5996 & 5996 \\
\hline \multirow[t]{3}{*}{ QAT } & Mean: & -0.1352 & 0.3003 & -0.2459 & 0.3503 & 0.4367 \\
\hline & SD: & 0.9342 & 1.1725 & 1.1856 & 0.7917 & 1.2538 \\
\hline & $\mathrm{N}$ & 9212 & 9212 & 9212 & 9212 & 9212 \\
\hline \multirow[t]{3}{*}{ SAU } & Mean: & 0.1430 & -0.2362 & -1.0362 & -0.6020 & 0.0485 \\
\hline & SD: & 1.0294 & 1.0631 & 1.1986 & 1.1589 & 1.1284 \\
\hline & $\mathrm{N}$ & 3324 & 3324 & 3324 & 3324 & 3324 \\
\hline \multirow[t]{3}{*}{ TUR } & Mean: & -0.1017 & -1.0443 & -0.4324 & -1.1197 & -1.3088 \\
\hline & SD: & 1.0351 & 0.9434 & 1.0384 & 1.1838 & 0.9456 \\
\hline & $\mathrm{N}$ & 5819 & 5819 & 5819 & 5819 & 5819 \\
\hline
\end{tabular}

Note: These are the weighted figures used as inputs for the pair-wise t-test in Excel "MegaStat"

The graphical results from the cross-country clustered bar charts of the weighted mean and standard deviation of the standardized well-being index are shown in figure (6) below. From the mean results in panel 1 (lower part), it can be noted that only the youth from Saudi Arabia report above average OECD level well-being, at 14.3\% standard deviation more. The remaining four Middle Eastern countries in the sample present below OECD level average youth subjective well-being. More specifically, youth from the UAE show an average well-being index value $4.57 \%$ standard deviations below the OECD youth average, while youth from Jordan, Turkey, and Qatar report respectively an average well-being index value $9.97 \%$, $10.17 \%$, and $13.52 \%$ standard deviations below the OECD average youth well-being.

The pair-wise t-test results with $99 \%$ confidence interval (C.I.) on the index of youth subjective well-being shown in table (2) below, further confirm the graphical results from the clustered bar charts. Indeed, it can be noted from table (2) that Saudi Arabia leads the five countries with a significant $24.47 \%$ higher average reported youth well-being than its immediate follower, the UAE. Similarly, the UAE presents a significant 5.61\% higher average reported youth wellbeing than the next in line, Turkey. Although Turkey presents a $0.2 \%$ higher average reported youth well-being than the following country Jordan, this effect is not statistically significant. Finally, youth from Qatar are found to report the lowest average well-being among the five countries in the study, at a significant $3.34 \%$ and $3.55 \%$ lower level than Turkey and Jordan respectively. 


\section{Subjective well-being Index}

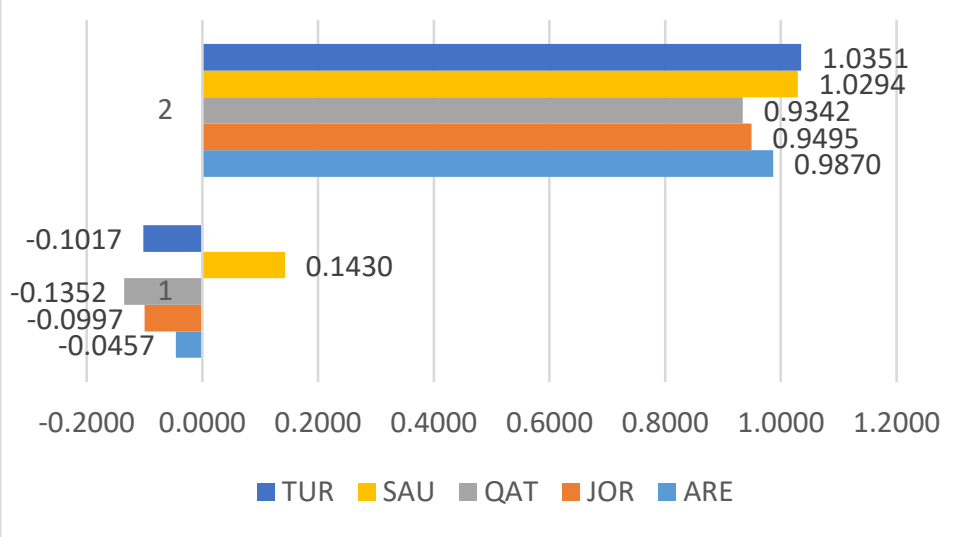

Figure 6: cross-country clustered bar chart of the weighted means (1) and standard deviations (2) of the standardized well-being index- BELONG.

Table 2: Pair wise t-test results with 99\% C.I. on the index of youth subjective well-being- BELONG.

\begin{tabular}{|c|c|c|c|c|c|c|}
\hline & ARE & JOR & QAT & SAU & TUR & RANK \\
\hline ARE & & $\begin{array}{l}\mu_{d}=0.0541^{* * *} \\
s . e_{d}=0.0149 \\
\text { p-value }=.0003 \\
(0.0156 ; 0.0925)\end{array}$ & $\begin{array}{l}\mu_{d}=0.0895^{\star \star \star} \\
s . e \cdot d=0.0129 \\
p-\text {-value }=4.71 \mathrm{E}-12 \\
(0.0562 ; 0.1228)\end{array}$ & $\begin{array}{l}\mu_{d}=-0.1886^{\star \star \star} \\
s . e \cdot d=0.0198 \\
p-\text {-value }=2.32 \mathrm{E}-21 \\
(-0.2396 ;-0.1376)\end{array}$ & $\begin{array}{l}\mu_{d}=0.0561^{* * *} \\
s . e_{\cdot d}=0.0160 \\
\text { p-value }=.0005 \\
(0.0148 ; 0.0974)\end{array}$ & 2 \\
\hline JOR & & & $\begin{array}{l}\mu_{d}=0.0355^{\star *} \\
s . e \cdot d=0.0157 \\
\text { p-value }=.0236 \\
(-0.0049 ; 0.0758)\end{array}$ & $\begin{array}{l}\mu_{d}=-0.2427^{* * *} \\
\text { s. } e \cdot d=0.0217 \\
\text { p-value }=7.22 \mathrm{E}-29 \\
(-0.2985 ;-0.1869)\end{array}$ & $\begin{array}{l}\mu_{d}=0.0020 \\
s . e \cdot d=0.0183 \\
\text { p-value }=.9113 \\
(-0.0451 ; 0.0492)\end{array}$ & 4 \\
\hline QAT & & & & $\begin{array}{l}\mu_{d}=-0.2781^{* * *} \\
s . e \cdot d=0.0203 \\
\text { p-value }=6.87 \mathrm{E}-42 \\
(-0.3305 ;-0.2257)\end{array}$ & $\begin{array}{l}\mu_{d}=-0.0334^{*} \\
s . e \cdot d=0.0167 \\
p-\text { value }=.0454 \\
(-0.0764 ; 0.0096)\end{array}$ & 5 \\
\hline SAU & & & & & $\begin{array}{l}\mu_{d}=0.2447^{\star \star \star} \\
s . e \cdot d=0.0224 \\
\text { p-value }=1.68 \mathrm{E}-27 \\
(0.1869 ; 0.3025)\end{array}$ & 1 \\
\hline TUR & & & & & & 3 \\
\hline
\end{tabular}

Note: $* * *$ indicates significance at $0.01 \%$ level, $* *$ at $1 \%$ level, and $*$ at the $5 \%$ level respectively

Relying on the standardized ICT resource index, the graphical results from the cross-country clustered bar charts of its weighted mean and standard deviation depict a different story than that of the well-being index above described. Indeed from the mean results in figure (7) panel 1 (lower part), it can be noted that the UAE and Qatar are the only two countries among the five, with above OECD level average of ICT resources available to their youth populations. More specifically, youth from the UAE and Qatar report on average $43.16 \%$ and $30.03 \%$ Standard deviations more ICT resources respectively than their OECD counterparts. Conversely however, youth from the remaining three countries (Saudi Arabia, Jordan, and Turkey) report respectively having $(23.62 \%, 87.12 \%$, and over $100 \%$ standard deviations) less ICT resources available at home than the average youth from OECD countries. 


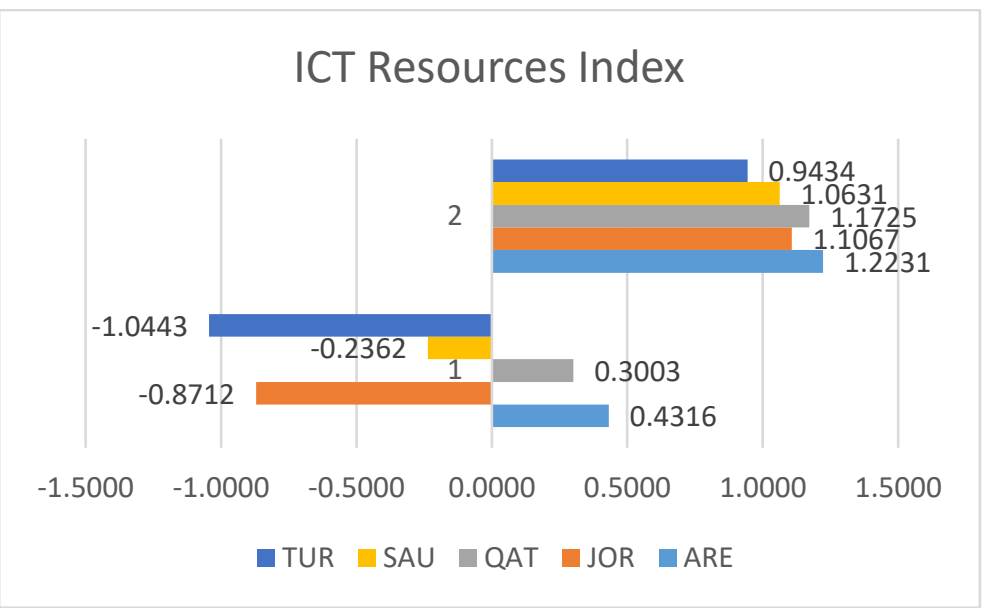

Figure 7: cross-country clustered bar chart of the weighted means (1) and standard deviations (2) of the standardized ICT resources index- ICTRES.

Now turning our attention to the pair-wise t-test results with $99 \%$ C.I. on the ICT resource index as shown in table (3) below, we observe significant in-sample cross-country heterogeneity in ICT resource availability to youth. Indeed, ranking in first position, the UAE shows a significant $13.13 \%$ higher average value for the index of ICT resource availability than the second country in line, which is Qatar. Similarly, Qatar shows a significant 53.65\% higher average value for this index than its follower, Saudi Arabia. In turn Saudi Arabia also highlights a significant $63.50 \%$ higher average value for the index than its follower, Jordan. Finally youth from Jordan report $17.31 \%$ significantly more ICT resources at home than their counterparts from Turkey.

Table 3: Pair wise t-test results with $99 \%$ CI on the ICT resources availability index- ICTRES.

\begin{tabular}{|c|c|c|c|c|c|c|}
\hline & ARE & JOR & QAT & SAU & TUR & RANK \\
\hline ARE & & $\begin{array}{l}\mu_{d}=1.3028^{\star * *} \\
\text { s. } e_{\cdot d}=0.0178 \\
\text { p-value }=0.00 \mathrm{E}+00 \\
(1.2570 ; 1.3486)\end{array}$ & $\begin{array}{l}\mu_{d}=0.1313^{\star \star \star} \\
s . e \cdot d=0.0161 \\
\text { p-value }=4.58 \mathrm{E}-16 \\
(0.0897 ; 0.1729)\end{array}$ & $\begin{array}{l}\mu_{d}=0.6678^{\star * *} \\
s . e \cdot d=0.0212 \\
\text { p-value }=4.26 \mathrm{E}-200 \\
(0.6130 ; 0.7226)\end{array}$ & $\begin{array}{l}\mu_{d}=1.4759^{* * *} \\
\text { s. } e \cdot d=0.0163 \\
\text { p-value }=0.00 \mathrm{E}+00 \\
(1.4340 ; 1.5178)\end{array}$ & 1 \\
\hline JOR & & & $\begin{array}{l}\mu_{d}=-1.1715^{\star \star *} \\
s . e \cdot d=0.0188 \\
\text { p-value }=0.00 \mathrm{E}+00 \\
(-1.2200 ;-1.1231)\end{array}$ & $\begin{array}{l}\mu_{d}=-0.6350^{* * *} \\
\text { s. } e \cdot d=0.0233 \\
\text { p-value }=2.84 \mathrm{E}-155 \\
(-0.6951 ; 0.5749)\end{array}$ & $\begin{array}{l}\mu_{d}=0.1731^{\star \star \star} \\
s . e_{\cdot d}=0.0189 \\
\text { p-value }=6.23 \mathrm{E}-20 \\
(0.1244 ; 0.2217)\end{array}$ & 4 \\
\hline QAT & & & & $\begin{array}{l}\mu_{d}=0.5365^{\star \star \star} \\
\text { s. } e_{\cdot d}=0.0221 \\
\text { p-value }=1.86 \mathrm{E}-124 \\
(0.4795 ; 0.5935)\end{array}$ & $\begin{array}{l}\mu_{d}=1.3446^{* * *} \\
\text { s.e.d }=0.0174 \\
\text { p-value }=0.00 \mathrm{E}+00 \\
(1.2998 ; 1.3894)\end{array}$ & 2 \\
\hline SAU & & & & & $\begin{array}{l}\mu_{d}=0.8081^{* * *} \\
s . e \cdot d=0.0222 \\
\text { p-value }=2.77 \mathrm{E}-263 \\
(0.7509 ; 0.8653)\end{array}$ & 3 \\
\hline TUR & & & & & & 5 \\
\hline
\end{tabular}

Note: $* * *$ indicates significance at $0.01 \%$ level, $* *$ at $1 \%$ level, and $*$ at the $5 \%$ level respectively

The graphical results from the cross-country clustered bar charts of the weighted mean and standard deviation of the standardized home educational resources index (HEDRES) are shown in figure (8) below. From the mean results in panel 1 (lower part), it can be noted that collectively youth from all five countries report below average OECD level home educational 
resources. More specifically, youth from the UAE report an average index value of $0.6 \%$ standard deviations below the OECD youth average, while youth respondents from Qatar, Turkey, Jordan and Saudi Arabia report respectively an average of 24.59\%, 43.24\%, 83.48\% and over $100 \%$ standard deviations below the OECD average youth home educational resources. The pair-wise t-test results with $99 \%$ C.I. on the index of youth home educational resources are further shown in table (4) below, and also confirm the graphical results from the clustered bar charts. Indeed, it can be noted that the United Arab Emirates leads the five countries with a significant $23.98 \%$ higher average youth reported home educational resources than its follower, which is Qatar. Similarly, Qatar presents a significant $18.65 \%$ higher average reported youth access to educational resources at home than the next in line, Jordan. Finally youth from Jordan report a significant $20.14 \%$ higher average access to educational resources at home than their counterparts in Saudi Arabia, which presents the lowest index value among the five countries.

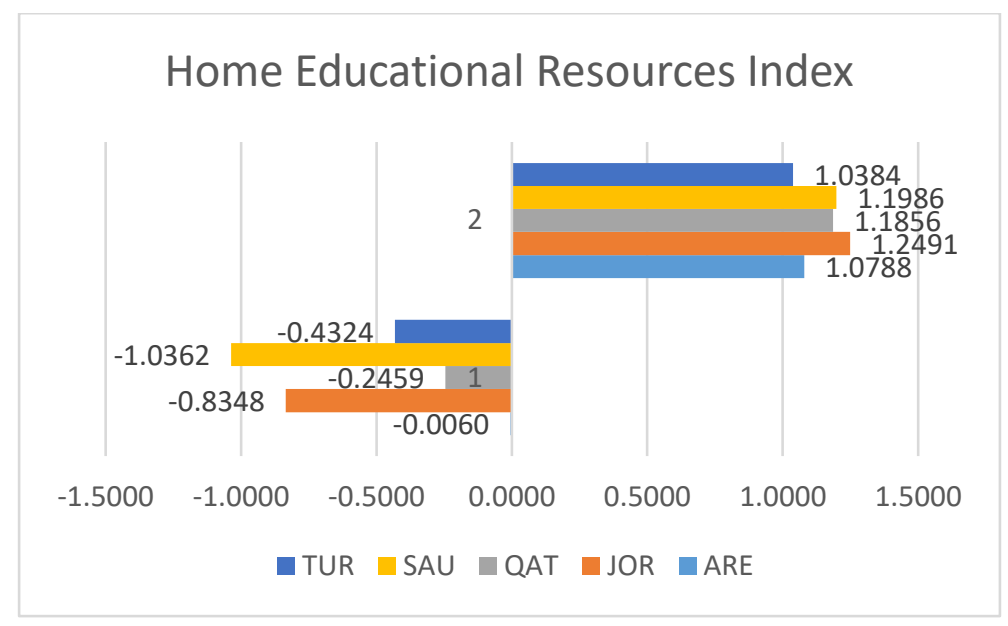

Figure 8: cross-country clustered bar chart of the weighted means (1) and standard deviations (2) of the standardized Home educational resources index- HEDRES

Table 4: Pair wise t-test results with $99 \% \mathrm{CI}$ on the Home Educational Resources Index- HEDRES

\begin{tabular}{|c|c|c|c|c|c|c|}
\hline & ARE & JOR & QAT & SAU & TUR & RANK \\
\hline ARE & & $\begin{array}{l}\mu_{d}=0.8287^{* * *} \\
s . e_{\cdot d}=0.0186 \\
\text { p-value }=0.00 \mathrm{E}+00 \\
(0.7807 ; 0.8767)\end{array}$ & $\begin{array}{l}\mu_{d}=0.2398^{\star \star *} \\
s . e \cdot d=0.0155 \\
\text { p-value }=7.36 \mathrm{E}-54 \\
(0.2000 ; 0.2797)\end{array}$ & $\begin{array}{l}\mu_{d}=1.0301^{* * *} \\
s . e \cdot d=0.0228 \\
\text { p-value }=0.00 \mathrm{E}+00 \\
(0.9714 ; 1.0889)\end{array}$ & $\begin{array}{l}\mu_{d}=0.4264^{* * *} \\
s . e_{d}=0.0165 \\
\text { p-value }=3.06 \mathrm{E}-143 \\
(0.3839 ; 0.4689)\end{array}$ & 1 \\
\hline JOR & & & $\begin{array}{l}\mu_{d}=-0.5889^{\star \star *} \\
s . e_{d}=0.0203 \\
\text { p-value }=9.77 \mathrm{E}-179 \\
(-0.6412 ;-0.5365)\end{array}$ & $\begin{array}{l}\mu_{d}=0.2014^{* * *} \\
s . e \cdot d=0.0263 \\
\text { p-value }=2.20 \mathrm{E}-14 \\
(0.1336 ; 0.2692)\end{array}$ & $\begin{array}{l}\mu_{d}=-0.4023^{* * *} \\
s . e \cdot d=0.0211 \\
\text { p-value }=8.86 \mathrm{E}-80 \\
(-0.4567 ;-0.3480)\end{array}$ & 4 \\
\hline QAT & & & & $\begin{array}{l}\mu_{d}=0.7903^{* * *} \\
s . e \cdot d=0.0242 \\
p-\text { value }=3.04 \mathrm{E}-22 \\
(0.7280 ; 0.8526)\end{array}$ & $\begin{array}{l}\mu_{d}=0.1865^{\star * *} \\
\text { s. } e_{\cdot d}=0.0184 \\
\text { p-value }=4.12 \mathrm{E}-24 \\
(0.1392 ; 0.2339)\end{array}$ & 2 \\
\hline SAU & & & & & $\begin{array}{l}\mu_{d}=-0.6038^{* \star *} \\
s . e_{d}=0.0248 \\
\text { p-value }=1.39 \mathrm{E}-124 \\
(-0.6678 ;-0.5397)\end{array}$ & 5 \\
\hline TUR & & & & & & 3 \\
\hline
\end{tabular}

Note: $* * *$ indicates significance at $0.01 \%$ level, $* *$ at $1 \%$ level, and $*$ at the $5 \%$ level respectively 
Now turning our attention to the standardized index of economic and socio-cultural status (ESCS), the graphical results from the cross-country clustered bar charts of its weighted means and standard deviations are depicted in figure (9). From the mean results in panel 1 (lower part), it can be noted that Qatar and the UAE are the only two countries among the five, with above OECD level average youth ESCS index value. More specifically, youth from Qatar and the UAE show respectively on average $35.03 \%$ and $33.69 \%$ Standard deviation higher Socioeconomic and cultural status than their OECD counterparts. Conversely however, youth from the remaining three countries (Jordan, Saudi Arabia, and Turkey) report respectively on average (58.96\%, 60.20\%, and over 100\% standard deviations) lower economic and socio-cultural status than the average youth among OECD Countries.

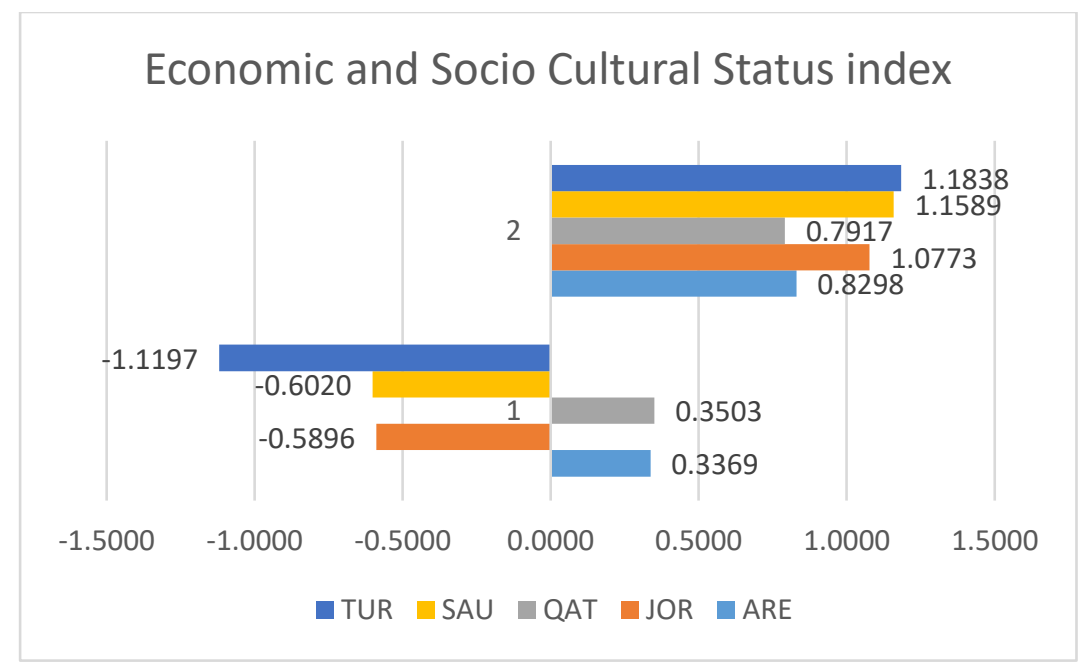

Figure 9: cross-country clustered bar chart of the weighted means (1) and standard deviations (2) of the standardized index of economic and socio-cultural status- ESCS.

Table 5: Pair wise t-test results with $99 \%$ CI on the Economic and Socio Cultural Status index- ESCS

\begin{tabular}{|c|c|c|c|c|c|c|}
\hline & ARE & JOR & QAT & SAU & TUR & RANK \\
\hline ARE & & $\begin{array}{l}\mu_{d}=0.9265^{\star \star \star} \\
s . e \cdot d=0.0157 \\
\text { p-value }=0.00 \mathrm{E}+00 \\
(0.8862 ; 0.9668)\end{array}$ & $\begin{array}{l}\mu_{d}=-0.0133 \\
s . e \cdot d=0.0109 \\
p-\text { value }=.2223 \\
(-0.0415 ; 0.0148)\end{array}$ & $\begin{array}{l}\mu_{d}=0.9390^{\star * \star} \\
s . e_{\cdot d}=0.0213 \\
\text { p-value }=0.00 \mathrm{E}+00 \\
(0.8840 ; 0.9940)\end{array}$ & $\begin{array}{l}\mu_{d}=1.4566^{* * *} \\
s . e_{d}=0.0171 \\
\mathrm{p}-\text {-value }=0.00 \mathrm{E}+00 \\
(1.4125 ; 1.5006)\end{array}$ & 2 \\
\hline JOR & & & $\begin{array}{l}\mu_{d}=-0.9398^{* * *} \\
s . e_{d}=0.0162 \\
\mathrm{p}-\text {-value }=0.00 \mathrm{E}+00 \\
(-0.9815 ;-0.8982)\end{array}$ & $\begin{array}{l}\mu_{d}=0.0125 \\
s . e \cdot d=0.0244 \\
\text { p-value }=.6100 \\
(-0.0505 ; 0.0755)\end{array}$ & $\begin{array}{l}\mu_{d}=0.5301^{* * *} \\
s . e_{d}=0.0208 \\
\text { p-value }=6.57 \mathrm{E}-139 \\
(0.4764 ; 0.5838)\end{array}$ & 3 \\
\hline QAT & & & & $\begin{array}{l}\mu_{d}=0.9523^{* * *} \\
s . e_{d}=0.0217 \\
\text { p-value }=0.00 \mathrm{E}+00 \\
(0.8963 ; 1.0083)\end{array}$ & $\begin{array}{l}\mu_{d}=1.4699^{\star * *} \\
S . e_{d}=0.0176 \\
\text { p-value }=0.00 \mathrm{E}+00 \\
(1.4246 ; 1.5152)\end{array}$ & 1 \\
\hline SAU & & & & & $\begin{array}{l}\mu_{d}=0.5176^{* * *} \\
s . e \cdot d=0.0254 \\
\text { p-value }=9.05 \mathrm{E}-90 \\
(0.4522 ; 0.5830)\end{array}$ & 4 \\
\hline TUR & & & & & & 5 \\
\hline
\end{tabular}

Note: $* * *$ indicates significance at $0.01 \%$ level, $* *$ at $1 \%$ level, and $*$ at the $5 \%$ level respectively 
Finally looking at the wealth index results as summarized in figure (10) and table (6) respectively below, the graphical results from the cross-country clustered bar charts depict a better story for most of the countries in the study. Indeed from the weighted mean results in panel 1 (lower part), it can be noted that all member countries of the Gulf cooperation council (GCC) in the data show above OECD level average wealth, while the remaining non-GCC countries (Jordan and Turkey) in the sample show below OECD level average wealth. More specifically, youth from the UAE, Qatar and Saudi Arabia report respectively on average $53.79 \%, 43.67 \%$ and $4.85 \%$ standard deviations more wealth than their OECD counterparts. Conversely however, youth from Jordan and Turkey report on average $96.4 \%$ and over 100\% standard deviations less wealth respectively, than the average youth among OECD Countries.

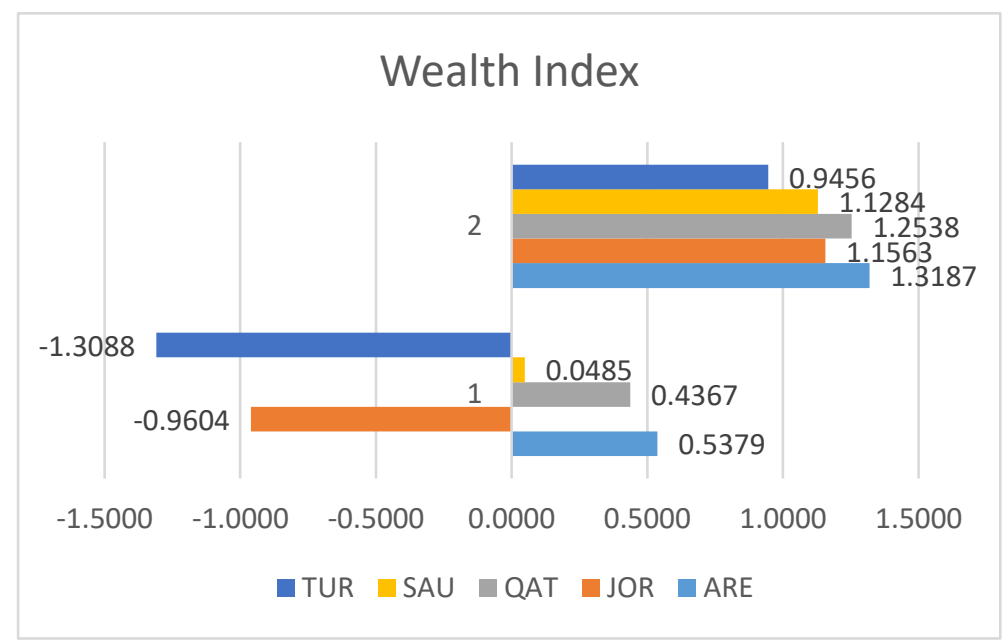

Figure 10: cross-country clustered bar chart of the weighted means (1) and standard deviations (2) of the standardized wealth index- WEALTH.

Table 6: Pair wise t-test results with 99\% CI on the Wealth Index- WEALTH.

\begin{tabular}{|c|c|c|c|c|c|c|}
\hline & ARE & JOR & QAT & SAU & TUR & RANK \\
\hline ARE & & $\begin{array}{l}\mu_{d}=1.4983^{\star * *} \\
s . e \cdot d=0.0188 \\
\text { p-value }=0.00 \mathrm{E}+00 \\
(1.4499 ; 1.5466)\end{array}$ & $\begin{array}{l}\mu_{d}=0.1012^{* \star \star} \\
s . e \cdot d=0.0173 \\
\text { p-value }=5.40 \mathrm{E}-09 \\
(0.0565 ; 0.1458)\end{array}$ & $\begin{array}{l}\mu_{d}=0.4894^{* \star *} \\
s . e \cdot d=0.0226 \\
\text { p-value }=1.09 \mathrm{E}-99 \\
(0.4311 ; 0.5477)\end{array}$ & $\begin{array}{l}\mu_{d}=1.8467^{\star \star *} \\
\text { s. } e_{d}=0.0168 \\
\mathrm{p} \text {-value }=0.00 \mathrm{E}+00 \\
(1.8033 ; 1.8901)\end{array}$ & 1 \\
\hline JOR & & & $\begin{array}{l}\mu_{d}=-1.3971^{* \star *} \\
s . e \cdot d=0.0198 \\
\mathrm{p}-\text { value }=0.00 \mathrm{E}+00 \\
(-1.4482 ;-1.3460)\end{array}$ & $\begin{array}{l}\mu_{d}=-1.0089^{* * *} \\
s . e \cdot d=0.0246 \\
\mathrm{p}-\text { value }=0.00 \mathrm{E}+00 \\
(-1.0723 ;-0.9454)\end{array}$ & $\begin{array}{l}\mu_{d}=0.3484^{* * *} \\
s . e \cdot d=0.0194 \\
p-\text { value }=4.16 \mathrm{E}-71 \\
(0.2984 ; 0.3984)\end{array}$ & 4 \\
\hline QAT & & & & $\begin{array}{l}\mu_{d}=0.3882^{* \star *} \\
s . e_{d}=0.0235 \\
\text { p-value }=6.14 \mathrm{E}-60 \\
(0.3276 ; 0.4489)\end{array}$ & $\begin{array}{l}\mu_{d}=1.7456^{* * *} \\
s . e_{d}=0.0180 \\
\text { p-value }=0.00 \mathrm{E}+00 \\
(1.6992 ; 1.7920)\end{array}$ & 2 \\
\hline SAU & & & & & $\begin{array}{l}\mu_{d}=1.3573^{* * *} \\
\text { s. } e_{d}=0.0232 \\
\mathrm{p}-\text {-value }=0.00 \mathrm{E}+00 \\
(1.2976 ; 1.4170)\end{array}$ & 3 \\
\hline TUR & & & & & & 5 \\
\hline
\end{tabular}

Note: $* * *$ indicates significance at $0.01 \%$ level, $* *$ at $1 \%$ level, and $*$ at the $5 \%$ level respectively 


\subsection{The Econometric results}

The implementation of the spatial bivariate copula regression model described in section 3.2 for the analysis of youth access to ICT resources and subjective well-being in the Middle East, using the 2018 PISA data requires the specification of a system of five equations as shown in the appendix. The first two equations in the system are the conditional mean equations (mu.1), describing respectively the means of the distributions of youth access to ICT resources at home, conditional on a set of covariates, and youth subjective well-being (mu.2) also conditional on a set of covariates.

The next two equations are the conditional variance equations, which describe respectively the variances of the distributions of youth access to ICT resources at home (sigma2.1), and youth subjective well-being (sigma2.2), all conditional on a set of covariates, and across the five countries covered by the study sample. The fifth equation (theta) models the conditional correlation between the two outcome variables (Youth access to ICT resources, and youth subjective well-being) to establish the sign and strength of the relationship between them. Since each youth respondent in the sample has a unique probability weight assigned for representativeness in the overall youth population within each country, estimation of our specified system of five equations incorporate these weights for variance correction, hence producing a joint weighted regression model. Parameter estimation is carried out within a penalized maximum likelihood framework as described in section 3.2, with integrated automatic multiple smoothing parameter selection. For interval construction and hypothesis testing, known and reliable inferential results from the smoothing literature are employed, with results described next.

\subsubsection{Dependence parameter results}

Recall from section 3.2, that dependence in our specified equation system is established by the (non)significance of the correlation parameter (theta) between the two equations, but also Kendall's tau parameter. The overall estimated value of the Kendall parameter $\hat{\tau}=0.012$ is positive with $95 \%$ confidence interval $(0.00308,0.0212)$, which is void of zero. Similarly the estimated correlation parameter $\hat{\theta}=0.0188$ with $95 \%$ confidence interval $(0.00481,0.0332)$. Together these results suggest a weak yet significant positive relationship between youth access to ICT resources and subjective well-being among the five Middle Eastern countries in our study sample.

Further cross country investigations of this dependence using Kendall's tau suggest significant spatial heterogeneity across the five countries as shown in figure (11) below. Overall, it can be noted from figure (11) that the dependence link between ICT resources availability and youth subjective well-being is positive and the strongest in Saudi Arabia, followed by UAE and Qatar, then by Turkey, and finally Jordan that shows the weakest dependence link among the five countries in the study. 


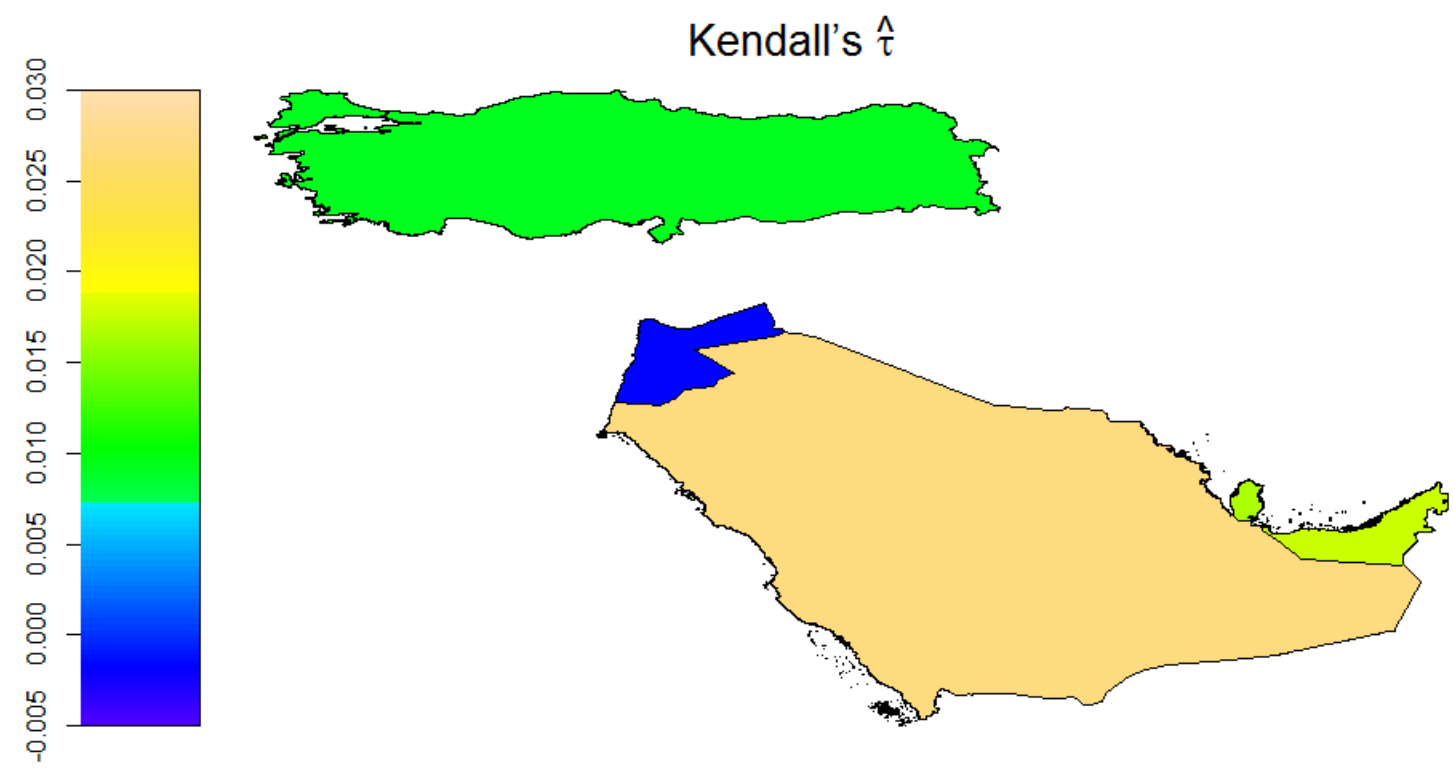

Figure 11: geographical maps of the cross-country heterogeneity in kendall's dependence parameter (tau). Estimated using the output of the spatial bivariate Gaussian copula regression model fitted to the PISA 2018 data.

\subsubsection{Conditional weighted mean equation results for youth access to ICT resources}

Summarized under ICTRES in the upper part of table (8), all the linearly entering predictors in the conditional weighted mean equation of youth access to ICT resources have statistically significant effects at the $0.1 \%$ level.

Overall, the results show that factors such as having a link to the internet at home, increased number of phones with internet access at home, increased number of computers at home, increased economic, social and cultural status, being a female, and speaking mostly at home the language of the PISA test, all contribute to raising the weighted likelihood of a youth scoring higher on the ICT resource index. More specifically every unit increase in the above enumerated factors raises respectively by $58.3 \%, 29.7 \%, 59.5 \%, 1 \%, 3.2 \%$, and $2.1 \%$ standard deviation, the weighted likelihood of greater access to ICT resources at home. Conversely however, every grade level increase in school between $7^{\text {th }}$ grade and $12^{\text {th }}$ grade, along with each standard deviation increase in the index of highest parental education (based on the international standard classification of education) appear to reduce respectively by $0.9 \%$ and $2.9 \%$ the weighted likelihood of a youth respondent scoring higher on the ICT resource index in the Middle Eastern region covered by the five countries in the study.

\subsubsection{Conditional weighted mean equation results for youth subjective well-being}

The estimated effect of the linearly entering predictors in the conditional weighted mean equation of youth subjective well-being (in terms of sense of belonging in school), are also summarized in the upper part of table (8) under "BELONG". With the p-values suggesting statistical significance at the $0.1 \%$ level, a unit increase in factors such as the number of phones with internet access at home, the index of parental education and the frequency of speaking the language of the PISA test at home, contribute to reducing respectively by $0.5 \%, 1.7 \%$ and 
$16.1 \%$ standard deviation the weighted likelihood of a youth respondent scoring higher on the subjective well-being index.

Conversely however, a unit increase in any of the remaining predictors such as the number of computers available at home, youth respondent grade level in school, economic social and cultural status, and being a female contribute to increasing respectively by $0.1 \%, 0.5 \%, 0.1 \%$, and $18.4 \%$ standard deviation the weighted likelihood of a youth respondent scoring higher on the subjective well-being index.

\subsubsection{Mean equations smooth function estimates for the continuous predictors}

The smooth function estimates for the continuous variables entering non-linearly the mean equations of youth access to ICT resources, and youth subjective well-being are shown in the lower portion of table (8), and further summarized in figure (12) and figure (13) respectively. Recall that, for these smooth function estimates, when the empirical density function (edf) is close to 1 , the respective estimated effect is linear, and hence the covariate can enter the model parametrically. However, the higher the edf value the more complex is the estimated curve, and thus the corresponding covariate cannot be assumed to have a linear relationship with the outcome variable.

As shown in the lower portion of table (8) under "ICTRES", the edfs for the smooth components of Age (8.786), expected occupation status (8.287), home educational resources availability (8.999) cultural possession at home (8.994) and country of residence (3.991) are all well above 1 , with statistically significant p-values at of $0.1 \%$ level. These indicate that all of the above continuous covariates have significant non-linear effects on youth access to ICT resources in the region. These algebraic results are further confirmed by the smooth functions plots in figure (12) below, which are estimated after fitting the spatial bivariate copula regression model to the 2018 PISA data. Indeed, the plots highlight significant non-linearity in youth access to ICT resources, across respectively from left to right: age, expected occupation status, home educational resources availability, and cultural possessions at home.
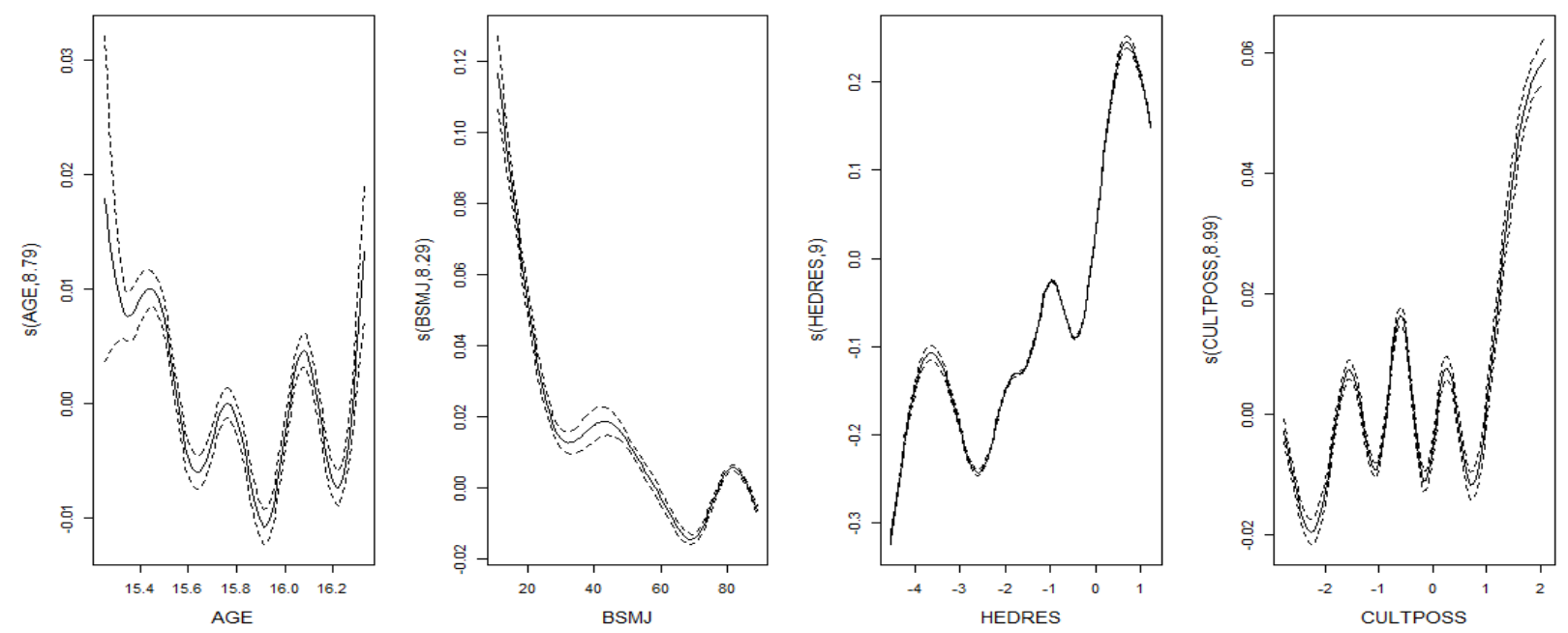

Figure 12: Smooth function estimates and $95 \%$ confidence bands for the continuous variables entering non-linearly the ICT resource availability equation. From left to right, these variables are respondents' age, expected occupation status, Home educational resources, and cultural possessions at home. These regression spline functions are estimated after fitting the spatial bivariate copula regression model to the data. 
Similarly the lower portion of table (8) under "BELONG" shows the edfs for the smooth components of Age (8.981), expected occupation status (8.946), home educational resources availability (8.969) and country of residence (3.999) for the continuous covariates entering nonlinearly the well-being equation. Since the edfs are all above 1 , with statistically significant $\mathrm{p}$ values at the $0.1 \%$ level, we have enough evidence to indicate the non-linear effect of the corresponding variables on youth subjective well-being in the Middle East. These algebraic results are also in line with the graphical smooth functions plots in figure (13), which highlight significant non-linearity in youth self-reported well-being, across respectively from left to right: age, expected occupation status, and home educational resources availability.
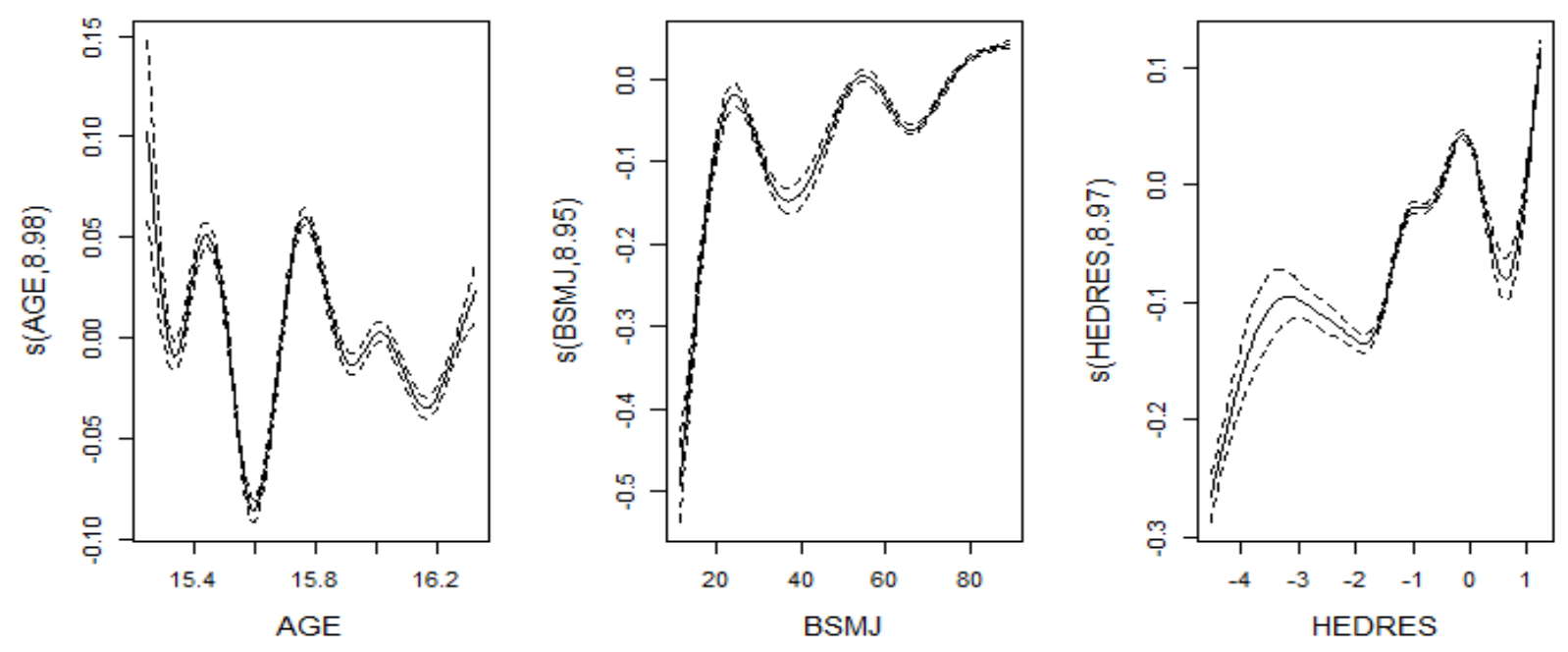

Figure 13: Smooth function estimates and 95\% confidence bands for the continuous variables entering non-linearly the well-being equation. From left to right, these variables are respondents' age, expected occupation status, and Home educational resources. These regression spline functions are estimated after fitting the spatial bivariate copula regression model to the data.

\subsubsection{Conditional weighted variance equations results:}

The conditional weighted variance equations results for both youth access to ICT resources and subjective well-being are summarized in table (9) under sigma2.1 and sigma2.2, with subsequent spatial representations in figure (14) to highlight the cross-country heterogeneity in national level ICT resources availability (left panel), and youth subjective well-being (right panel) across the five countries.

Focusing on the variance equation of youth access to ICT resources as shown under sigma2.1, it is estimated conditional on one linear predictor (ESCS), and three continuous non-linear predictors (Age, HEDRES, and country). The results show that a standard deviation increase in the index of economic, social and cultural status increases on average by $26.2 \%$ standard deviations, the variance in ICT resource availability to the youth population in the region. Similarly, the continuous predictors of sigma2.1 with respective Edfs of 8.849 for Age, 8.898 for HEDRES, and 3.999 for country, which are all greater than 1, are shown to have statistically significant and non-linear effects on the variance of ICT resource availability to youth, at the $0.1 \%$ level.

Moreover, controlling for all the above mentioned factors, the estimated average variation in ICT resource availability to the youth is 0.351 with $95 \%$ confidence interval $(0.344,0.358)$. This suggests a significant $35.1 \%$ standard deviation above OECD average variation in ICT 
resource access by the youth population in the Middle Eastern region covered by the five countries in the study.

Furthermore, the graphical representation of the cross-country heterogeneity on the left panel of figure (14) show that variability in ICT resources availability to the youth population is the highest in Turkey at clearly over 1.2 standard deviations above that of the OECD average, followed by Qatar at also over 1 standard deviation above the OECD average, then by Jordan at about ] 0.6 to 0.8 [ standard deviation above the OECD average, and finally by the UAE with the lowest standard deviation value among the five, at less than 0.6 standard deviations above the OECD average.
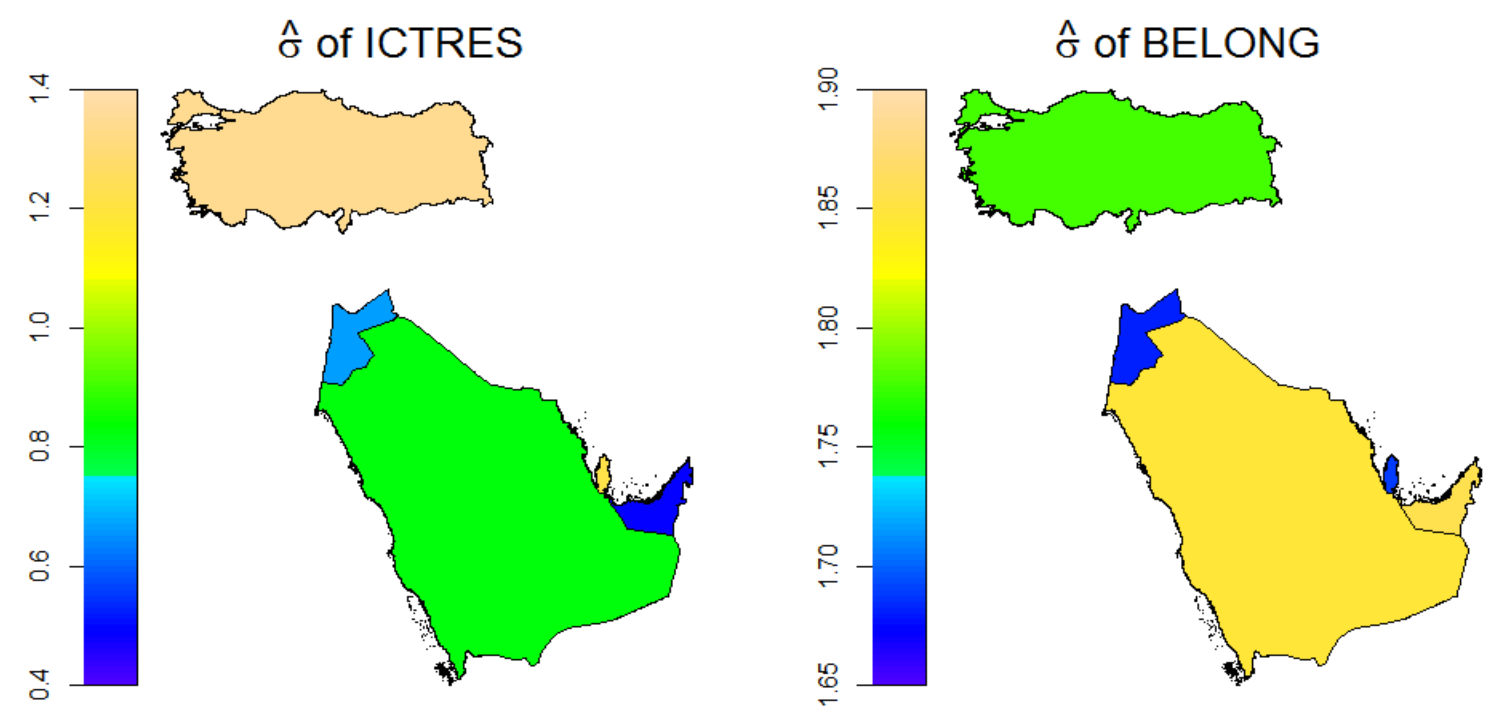

Figure 14: geographical maps of the cross-country heterogeneity in the estimated standard deviations of youth access to ICT resources (left panel) and youth subjective well-being (right panel). These are generated from the output of the fitted spatial bivariate Gaussian copula regression model to the PISA 2018 data.

Now turning our attention to sigma2.2 in table (9) in the appendix, it can be noted that all linear and non-linear predictors have significant effects on the conditional variance of youth subjective well-being in the Middle region covered by the five countries. In fact, the positive and significant 0.023 effect for the linear predictor (ESCS) suggests that every standard deviation increase in the index of Economic, social and cultural status increases on average by $2.3 \%$ standard deviation the variance in youth subjective well-being in the region. Similar significant effects are found with the continuous predictors of sigma2.2, with respective Edfs 8.734 for Age, 8.966 for CULTPOSS, 8.984 for HEDRES, and 3.863 for Country, which are all greater than 1 , suggesting non-linearity.

Controlling for the above linear and non-linear predictors, the estimated average variation in youth subjective well-being across the five Middle Eastern countries in the study is 0.938, with $95 \%$ confidence interval $(0.919,0.958)$, which is significant. This result indicates that even after controlling for relevant factors of variations in youth well-being in the region, a significant 93.8\% standard deviation above OECD average variation in subjective well-being is still present among the youth in the Middle Eastern region covered by the five countries. 
Moreover, the spatial mapping of the country level variations in youth subjective well-being as shown in the right panel of figure (14) above highlights significant heterogeneity. Indeed, the graphical map seems to indicate relatively greater variability in youth subjective well-being in the UAE and Saudi Arabia, followed by Turkey, and finally by Qatar and Jordan.

\subsubsection{Markov Random field smoother results for the spatial predictor}

The spatial results from the Markov Random Field "mrf" smoothers estimates of the cross-country variations in standardized ICT resource availability (left panel) and youth subjective well-being (right panel) are shown in figure (15) below.

Focusing on the left panel, it can be noted an apparent spatial effect in the distribution of ICT across the five countries in our study sample. Indeed, as we move south from Turkey in the northern part to the UAE in the south eastern part of the map, we observe an increased level of ICT resource availability across the five countries. These spatial econometric findings further corroborate with the cross-country clustered bar chart results in figure (8), and the Pair wise t-test results with $99 \%$ CI on the ICT resources availability index in table (4).

Now turning to the right panel of figure 12, we also note the presence of spatial heterogeneity in the distribution of youth subjective well-being across the five countries in our study. Indeed Saudi Arabia clearly leads the five with a clear above OECD average performance, followed by UAE, Jordan, Qatar and finally Turkey. Interestingly, these spatial econometric findings are directly supported by the previously described cross-country clustered bar chart results in figure (7), and the pair-wise t-test results with 99\% CI on the Youth subjective well-being index in table (3).
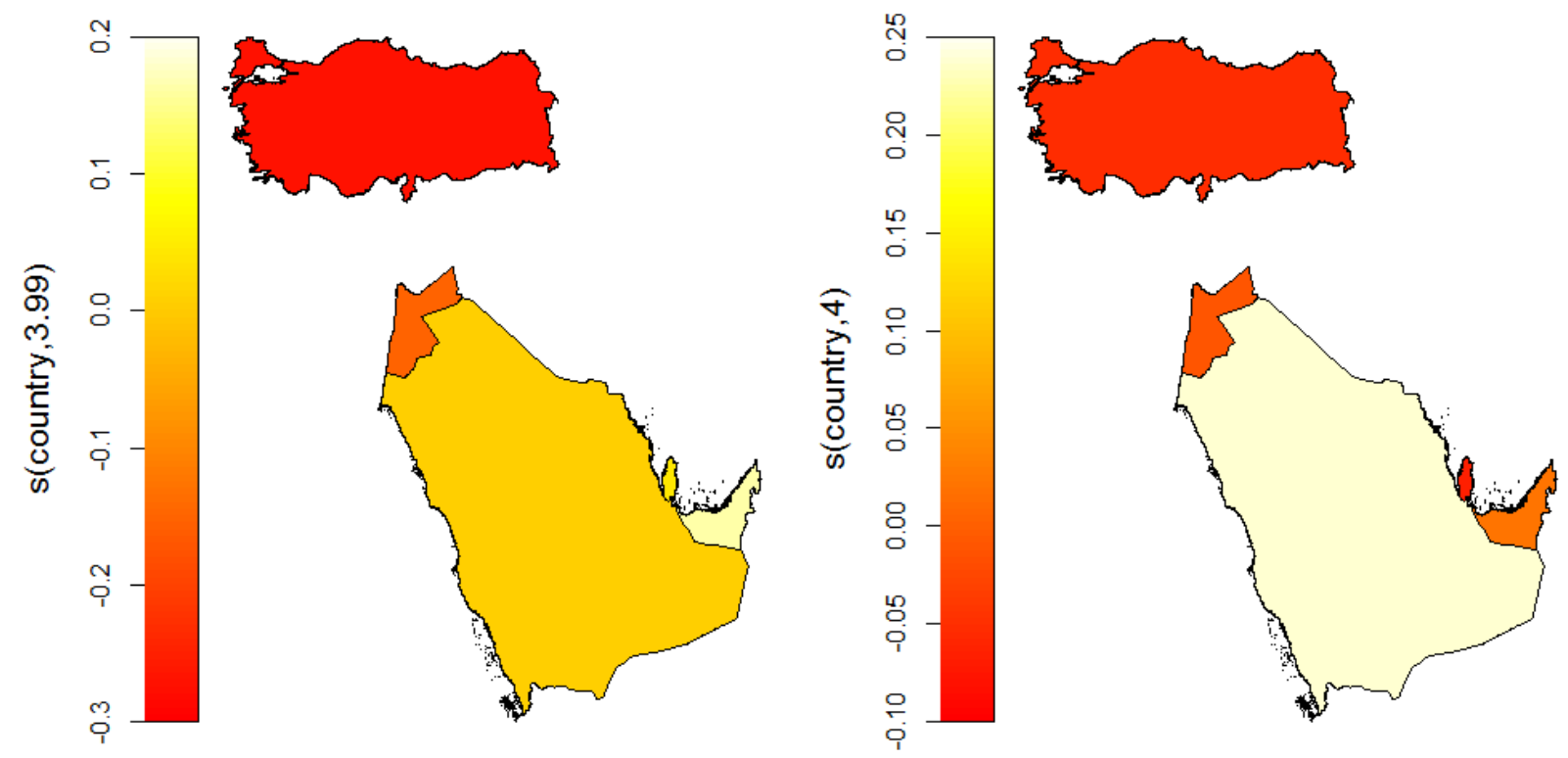

Figure 15: Markov Random Field "mrf" estimates of the cross-country spatial variations in standardized ICT resource availability (left panel) and youth subjective well-being (right panel). These are generated from the output of the fitted spatial bivariate Gaussian copula regression model to the PISA 2018 data. 


\section{Discussions}

Recall that the study had two major objectives, the first of which was to evaluate the availability and thus access to ICT resources by the youth population in the Middle East region post 2015 SDG adoption, while the second objective was to identify the impact of ICT resource availability on youth subjective well-being in the region post 2015 SDG adoption.

On the first objective, the results of our analysis showed that in relative terms, only the UAE and Qatar had above OECD level average ICT resources for their youth at home, while the remaining three countries in study had below OECD level average ICT resources for their youth at home. More specifically it was found that youth from the UAE and Qatar had respectively $43.16 \%$ and $30.03 \%$ standard deviations more ICT resources at home than their OECD counterparts, while youth from Saudi Arabia, Jordan and Turkey had respectively $23.62 \%$, $87.12 \%$ and over $100 \%$ standard deviations less ICT resources at home than their OECD counterparts.

The within region cross-country comparative analysis of ICT resources availability to the youth population at home, highlighted significant heterogeneity across the five countries in the Middle Eastern region covered by the study. Indeed, based on the ICT resource index, the UAE occupied the first position with a $13.13 \%$ higher index value than the second country in line, Qatar, which also showed a significant $53.65 \%$ higher index value than Saudi Arabia in third position. In turn, Saudi Arabia had 63.5\% more ICT resources for its youth at home, than the fourth country in line, Jordan; which also significantly exceeded by $17.31 \%$ the amount of ICT resources Turkey had for it youth at home.

Together, the above results show that as a region, most of the five Middle Eastern countries in the study perform below the OECD average on the ICT resource index, while only a few show above OECD average performance. In addition, significant inequalities in youth access to ICT resources exist across the five countries, post 2015 SDG adoption. Given the importance of youth access to ICT resources for national as well as regional economic development, a concerted effort by member countries in the region could assist not only each country in its own development path, but also the region as a whole to live up to its growth potential by 2030 .

On the second objective of the study to identify the impact of ICT resources availability on youth subjective well-being in the Middle East, Post 2015 SDG adoption, the evaluation using the 2018 PISA data depicted a somewhat different picture than that presented on the ICT resource index above.

Indeed, in relative terms, except for Saudi Arabia which showed a 14.3\% standard deviation higher subjective well-being for its youth population than the OECD average, all remaining four countries in the studied region showed below OECD level average youth subjective wellbeing post 2015 SDG adoption. More specifically, it was found that youth from the UAE reported on average $4.57 \%$ standard deviations below OECD average youth well-being, while those from Jordan, Turkey and Qatar reported respectively 9.97\%, 10.17\% and 13.52\% standard deviations below their OECD counterparts.

Moreover, the cross-country comparative analysis of youth subjective well-being across the five Middle Eastern countries further highlighted significant heterogeneity. Indeed, based on the subjective well-being index as captured by youth self-reported sense of belonging in school, the youth from Saudi Arabia reported the greatest sense of belonging at $24.47 \%$ higher than 
those from the UAE, whom reported $5.61 \%$ higher sense of belonging than their counterparts from Turkey. While youth from Turkey did not report significantly higher sense of belonging than their Jordanian counterparts, they both however had 3.34\% and 3.55\% higher sense of belonging in school than their counterparts in Qatar.

The results therefore show that although Qatar is one of the two countries with above OECD average ICT resources for its youth population post 2015 SDG adoption, youth from the country still report the least well-being in terms of subjective sense of belonging in school. On the other hand, despite the fact that Saudi Arabia was the third performing country on the ICT resource index, yet with below OECD average performance by $23.62 \%$ standard deviation, its youth still appeared to report the greatest well-being of all five countries, in terms of self-reported sense of belonging in school. These findings seem to not only suggest the presence of a non-linear relationship between national level ICT resource availability, and youth subjective well-being; but also point out to the fact that other factors affecting youth well-being need to be considered.

Hence our spatial bivariate copula regression modelling of youth access to ICT resources and subjective well-being, where we controlled for not only cross-country spatial correlations, but also factors such as home educational resources, cultural possessions at home, parental occupation status, youth expected occupation status, economic and socio-cultural status, age, gender, and grade level in school.

Overall, most control factors were consistent with their theoretical effects on the weighted likelihood of youth access to ICT resources, and subjective well-being. For example, the adverse effect of increased number of phones with internet access at home on youth subjective well-being, seems to corroborate with the plethora of writings on the impact of problematic phone use on youth well-being. Indeed, Elhai et al, (2019), Sha et al., (2019), and Sindermann et al., (2020) all report adverse psychological well-being effects on youth, while Domoff et al, (2019) and Rodgers et al, (2020) report such adverse effects on youth physical well-being; and Clayton et al, (2015) on their cognition, emotion, and physiology. On the other hand, the negative effects of increased grade level in school, and increased parental education on the weighted likelihood of youth access to ICT resources at home seemed a bit odd and counterintuitive. Further look into the potential reasons for such findings, might be warranted in a prospective investigation.

Nevertheless, after controlling for the above relevant factors, we found a correlation parameter value of 0.0188 with $95 \%$ confidence interval $(0.00449,0.0328)$ and a dependence parameter value of 0.0120 with $95 \%$ confidence interval $(0.00288,0.021)$ between the two outcome variables. These latter results suggest a positive dependence between youth access to ICT resources at home and their subjective well-being (self-expressed sense of belonging in school). More specifically, on average, controlling for other factors influencing the distribution of youth well-being in the region, every standard deviation increase in ICT resources to the youth population raised their self-expressed sense of belonging in school by $1.88 \%$ standard deviations. This dependence between the two outcomes is also seen to highlight significant cross-country heterogeneity from the spatial bivariate copula regression analysis. Hence, supporting further the idea that the focus of promoting well-being in one country may not be essentially the same from what is required in another country (Navarro et al., 2019).

Since the scientific evidence suggests that ICT resources have the greatest potential to empower youth and thereby raise their well-being (Loebach, 2019), and also because youth experiencing 
greater sense of holistic well-being are more able to learn and assimilate in effective ways (Clement, 2010; Wang \& Degol, 2016); more likely to engage in healthy and fulfilling social behaviors (Poulou \& Norwich, 2019), and more likely to invest in their own and others' wellbeing and in the sustainability of the planet as they embrace their social, professional and leadership roles in adulthood(Scales et al., 2016), each country will have to find a way to better assist its youth in this regard, while collaborating with regional country members in a concerted effort to assist not only each country in its own development path, but also the region as a whole to live up to its growth potential by the 2030 .

\section{Conclusions}

United Nations country members embraced in 2015 a global development agenda with 17 goals and numerous targets among which target 9.c "increasing access to information and communications technology and striving to provide universal and affordable access to the internet, especially in least developed countries by 2020". Today, nearly five years into implementation of SDG strategies, and in the dawn of the year 2020, the present study focused specifically on the experience of the youth population in five select countries in the Middle East region to (i) evaluate the availability and access to ICT resources to the youth population in the region post-2015 SDGs adoption, and (ii) identify the impact of ICT resources availability on youth subjective well-being in the region during the same period. We achieved these objectives using data from the 2018 PISA (OECD, 2019), covering the UAE, Qatar, Saudi Arabia, Jordan, and Turkey.

The analytical strategy relied on graphical cross-country clustered bar charts of the weighted mean and standard deviation of standardized indexes of youth access to ICT resources and subjective well-being in the region. This was followed by cross-country pair-wise hypothesis tests of difference in weighted mean index performances between the five countries in the study; and finally by a spatial bivariate copula regression modelling of the response variables, controlling for a host of factors affecting youth subjective well-being in terms of self-reported sense of belonging in school.

Overall, the results showed below OECD average performance on the ICT resource index for all countries, except the UAE and Qatar who performed well above their OECD counterparts. Furthermore, significant heterogeneity in ICT resources were found between the five countries, with youth from the UAE reporting the highest endowment, and their counterparts in Turkey reporting the lowest endowment among the five countries.

In the youth well-being dimension, it was found that despite the fact Qatar had the second highest endowments in ICT resources at home among the five countries, with its youth showing above OECD level average on the ICT resource index, youth from Qatar were also seen to report the least well-being in terms of subjective sense of belonging in school. Conversely however, youth from Saudi Arabia reported the greatest well-being among the five countries, despite having below OECD average ICT endowments, and being the third performing country on the ICT resource index among the five.

Together, these findings seemed to indicate that having the highest youth endowment in ICT resources does not necessarily lead to the best youth well-being outcome in terms of sense of belonging in school, and further point out the potential significance of other relevant factors 
that need to be considered to get the full picture. After controlling for such factors, we still found a positive and significant dependence between ICT resource availability and youth subjective well-being at the national level across all five countries.

Overall, in addition to meeting its two objectives, the present study also contributed methodologically to the literature on the topic through its usage of descriptive data analytics, and computational econometric methods for location, scale and spatial analyses, which have not yet been considered in the literature. Moreover, the study is also among the first to provide an early cross-country evaluation and ranking of national level performances on indicators relevant to the UN SDG target 9.c and even more so, for the Middle East region.

Given the cross sectional nature of the study sample however, the discussions in the paper were limited to the state of nature for the youth population in the region, post 2015 SDG adoption as captured in the 2018 PISA data. Possible avenues from here include quantifying the changes in ICT resources availability and youth well-being between 2015 and 2018, for not only youth in the Middle East region, but also enlarging the study population to include youth from other world regions. Such iterations will eventually be the subject of our next focus on the topic.

\section{Declaration of Interest:}

None 


\section{Appendix}

The final implemented model in the R statistical software is:

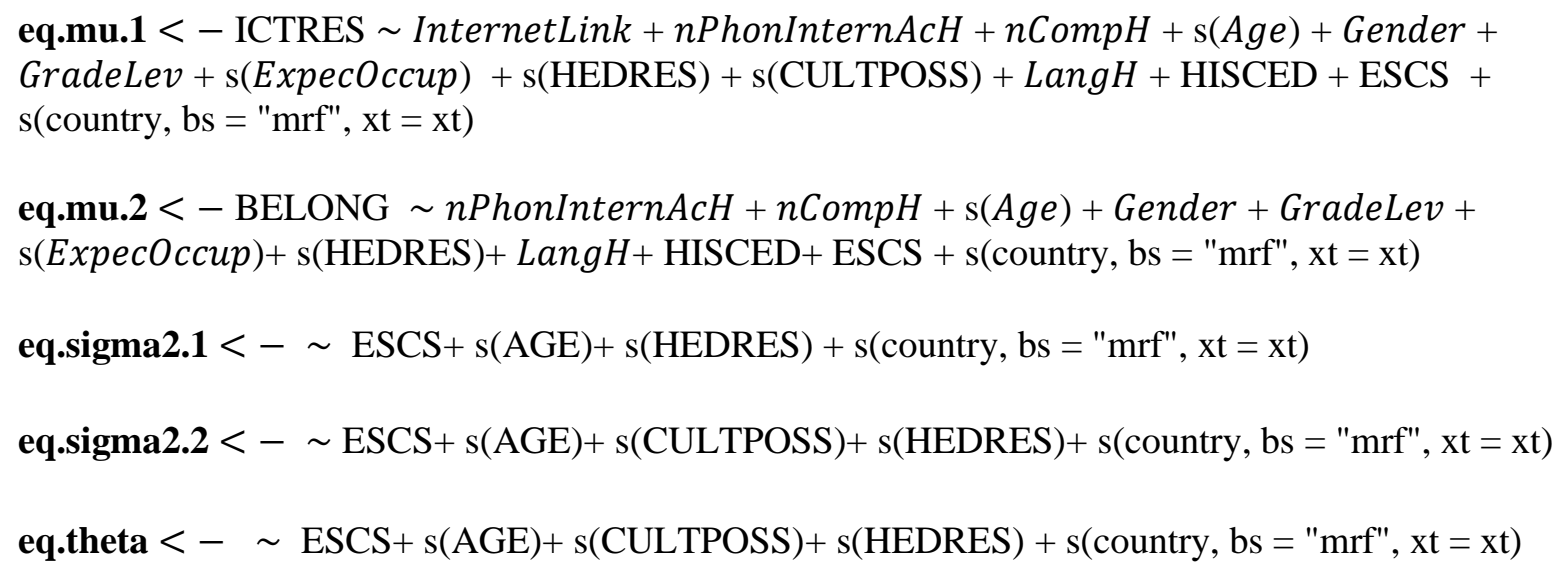

$\mathrm{fl}<-$ list(eq.mu.1, eq.mu.2, eq.sigma2.1, eq.sigma2.2, eq.theta)

woutC0 $<-$ copulaReg(fl, margins = c("N", "N"), data = GCCTJ_PISA_18, weights = W_FSTUWT, gc.l $=$ TRUE, gamlssfit $=$ TRUE, iterlimsp $=100$ )

Where the first two equations (eq.mu.1, eq.mu.2) refer to the $\mu$ parameters of ICTRES and BELONG, the third (eq.sigma2.1) and fourth (eq.sigma2.2) equations to the $\sigma^{2}$ parameters and the last equation (eq.theta) to the $\theta$ parameter. The Gaussian copula is used to join the two outcome variables (ICTRES, BELONG), with all parameters modeled using predictors involving factors, continuous and spatial variables. The model estimation procedure takes into account the respondents' level final weight "W_FSTUWT", used to correct for the complex sampling structure of the 2018 PISA data. Here the s(.) functions in the equations are used to smooth the effects of the continuous variables such as the respondent age, which might have non-linear effects on the response variables as previously described above. This practice allows us to avoid arbitrary modeling decisions which can induce misspecification bias. Similarly, the use of the Markov Random Field "mrf" smoothers on the spatial variable (country) in all equations ensures that the distribution of the estimated parameters vary smoothly across the five Middle Eastern countries covered by our study sample. See Marra \& Radice (2017) for more elaborate details on the above implementation procedure. 
Table (7): Summary statistics of the included variables in the analysis

\begin{tabular}{|c|c|c|c|c|}
\hline $\begin{array}{l}\text { Quantitative } \\
\text { Variables }\end{array}$ & & & Mean & S.d. \\
\hline BELONG & \multicolumn{2}{|c|}{$\begin{array}{l}\text { Sense of belonging to school (index of youth subjective } \\
\text { well-being) }\end{array}$} & -0.071 & 0.982 \\
\hline ICTRES & \multicolumn{2}{|c|}{ Index of ICT resources availability to youth at home } & -0.095 & 1.317 \\
\hline nPhonInternAcH & \multicolumn{2}{|c|}{ Number of Phones with internet access at home } & 3.691 & 0.724 \\
\hline nCompH & \multicolumn{2}{|c|}{ Number of computers at home (Desktop, Laptop, notebook) } & 2.844 & 1.056 \\
\hline $\mathrm{AGE}$ & \multicolumn{2}{|c|}{ student's age in years } & 15.803 & 0.293 \\
\hline ExpecOccup & \multicolumn{2}{|c|}{$\begin{array}{l}\text { student's expected occupational status by age } 30 \\
\text { (Ganzeboom and Treiman , 2003) }\end{array}$} & 73.078 & 15.829 \\
\hline HEDRES & \multicolumn{2}{|c|}{ Index of home educational resources availability } & -0.3745 & 1.196 \\
\hline CULTPOSS & \multicolumn{2}{|c|}{ Index of cultural possessions at home } & -0.557 & 0.978 \\
\hline HISCED & \multicolumn{2}{|c|}{$\begin{array}{l}\text { Index of highest education of parents (international standard } \\
\text { classification of education - ISCED) }\end{array}$} & 4.849 & 1.574 \\
\hline ESCS & \multicolumn{2}{|c|}{ Index of economic, social and cultural status } & -0.136 & 1.127 \\
\hline HISEI & \multicolumn{2}{|c|}{ Index of highest parental occupational status } & 56.894 & 23.174 \\
\hline W_FSTUWT & \multicolumn{2}{|c|}{ Final trimmed non-response adjusted student weight } & 28.264 & 47.530 \\
\hline $\begin{array}{l}\text { Qualitative } \\
\text { Variables }\end{array}$ & & & $\begin{array}{l}\text { Abs. } \\
\text { Freq. }\end{array}$ & $\begin{array}{l}\text { Rel. } \\
\text { Freq. }\end{array}$ \\
\hline \multirow[t]{2}{*}{ InternetLink } & \multirow[t]{2}{*}{ A link to the internet at home } & (1) Yes & 34603 & $91.64 \%$ \\
\hline & & (0) No & 3157 & $8.36 \%$ \\
\hline \multirow[t]{2}{*}{ Gender } & \multirow[t]{2}{*}{ Standardized gender } & (1) Female & 20672 & $54.75 \%$ \\
\hline & & (0) Male & 17088 & $45.25 \%$ \\
\hline \multirow{6}{*}{ GradeLev } & \multirow{6}{*}{$\begin{array}{l}\text { International grade level in } \\
\text { school }\end{array}$} & $7^{\text {th }}$ grade & 114 & $0.30 \%$ \\
\hline & & $8^{\text {th }}$ grade & 653 & $1.73 \%$ \\
\hline & & $9^{\text {th }}$ grade & 4988 & $13.21 \%$ \\
\hline & & $10^{\text {th }}$ grade & 26104 & $69.13 \%$ \\
\hline & & $11^{\text {th }}$ grade & 5632 & $14.92 \%$ \\
\hline & & $12^{\text {th }}$ grade & 269 & $0.71 \%$ \\
\hline \multirow[t]{2}{*}{ LangH } & \multirow{2}{*}{$\begin{array}{l}\text { Language spoken at home } \\
\text { most of the time }\end{array}$} & (1) Language of the test & 27637 & $73.19 \%$ \\
\hline & & (0) Other Language & 10123 & $26.81 \%$ \\
\hline \multirow{5}{*}{ Country } & \multirow{5}{*}{$\begin{array}{l}\text { Respondent's country of } \\
\text { residence }\end{array}$} & UAE & 13409 & $35.51 \%$ \\
\hline & & JORDAN & 5996 & $15.88 \%$ \\
\hline & & QATAR & 9212 & $24.40 \%$ \\
\hline & & SAUDI ARABIA & 3324 & $8.80 \%$ \\
\hline & & TURKEY & 5819 & $15.41 \%$ \\
\hline \multirow[t]{3}{*}{ IMMIG } & \multirow{3}{*}{$\begin{array}{l}\text { Respondent's immigration } \\
\text { status }\end{array}$} & (1) Native & 22961 & $60.81 \%$ \\
\hline & & (2) Second generation & 5347 & $14.16 \%$ \\
\hline & & (3) First generation & 9452 & $25.03 \%$ \\
\hline
\end{tabular}


Table (2): Mean Equations Results for youth Access to ICT resources and Subjective well-being

\begin{tabular}{|l|c|c|c|c|}
\hline \multirow{2}{*}{ Linear Predictors } & \multicolumn{2}{|c|}{ ICTRES } & \multicolumn{2}{c|}{ BELONG } \\
\cline { 2 - 5 } CONST & Est. & Std. err. & Est. & Std. err. \\
\hline InternetLink & $-3.269^{* * *}$ & 0.00694 & $-0.643^{* * *}$ & 0.00224 \\
\hline nPhonInternAcH & $0.583^{* * *}$ & 0.00075 & ----- & ---- \\
\hline nCompH & $0.297^{* * *}$ & 0.00039 & $-0.005^{* * *}$ & 0.00014 \\
\hline Gender (female) & $0.595^{* * *}$ & 0.00045 & $0.001^{* * *}$ & 0.00013 \\
\hline GradeLev & $0.032^{* * *}$ & 0.00057 & $0.182^{* * *}$ & 0.00021 \\
\hline LangH & $-0.009^{* * *}$ & 0.00059 & $0.005^{* * *}$ & 0.00020 \\
\hline HISCED & $0.021^{* * *}$ & 0.00106 & $-0.161^{* * *}$ & 0.00038 \\
\hline ESCS & $-0.029^{* * *}$ & 0.00031 & $-0.017^{* * *}$ & 0.00006 \\
\hline \multicolumn{5}{|l|}{} \\
\hline Non-linear Predictors & $0.010^{* * *}$ & 0.00065 & $0.001^{* * *}$ & 0.00001 \\
\hline Age & Edf & Chi.sq. & Edf & Chi.sq. \\
\hline ExpecOccup & $8.786^{* * *}$ & 486.8 & $8.981^{* * *}$ & 1462 \\
\hline HEDRES & $8.287^{* * *}$ & 2263.5 & $8.946^{* * *}$ & 2459 \\
\hline CULTPOSS & $8.999^{* * *}$ & 82570.8 & $8.969^{* * *}$ & 3773 \\
\hline Country & $8.994^{* * *}$ & 1953.5 & ----- & ---- \\
\hline
\end{tabular}

Table (3): Variances and dependence parameter Equations Results

\begin{tabular}{|c|c|c|c|c|c|c|}
\hline & \multicolumn{2}{|c|}{ Sigma2.1 } & \multicolumn{2}{|c|}{ Sigma2.2 } & \multicolumn{2}{|c|}{ Theta } \\
\hline Linear predictors & Est. & Std. err. & Est. & Std. err. & Est. & Std. err. \\
\hline CONST & $-1.307 * * *$ & 0.00443 & $-0.075 * * *$ & 0.00438 & $0.022 * * *$ & 0.00302 \\
\hline ESCS & $0.262 * * *$ & 0.00145 & $0.001 * * *$ & 0.00151 & $0.023 * * *$ & 0.00103 \\
\hline $\begin{array}{l}\text { Non-linear } \\
\text { Predictors }\end{array}$ & Edf & Chi.sq. & Edf & Chi.sq. & Edf & Chi.sq. \\
\hline Age & $8.849 * * *$ & 3966 & 8.949 & 1721 & $8.734 * * *$ & 1317.8 \\
\hline CULTPOSS & ----- & ----- & 8.854 & 6292 & 8.966 *** & 1171.3 \\
\hline HEDRES & $8.898 * * *$ & 6163 & 8.991 & 1490 & $8.984 * * *$ & 1359.3 \\
\hline Country & $3.999 * * *$ & 98586 & 3.993 & 1200 & $3.863 * * *$ & 229.4 \\
\hline $\begin{array}{l}\text { Model Performance } \\
\text { measures }\end{array}$ & $\begin{array}{l}\mathrm{Es} \\
(\mathrm{C} .\end{array}$ & & $\begin{array}{r}\mathrm{Es} \\
(\mathrm{C}\end{array}$ & & & \\
\hline$\hat{\sigma}_{21}$ & $\begin{array}{r}0.3 \\
(0.344,\end{array}$ & $\begin{array}{l}51 \\
0.358)\end{array}$ & & & & \\
\hline$\hat{\sigma}_{22}$ & & & $\begin{array}{r}0.9 \\
(0.919\end{array}$ & $\begin{array}{l}38 \\
0.958)\end{array}$ & & \\
\hline$\widehat{\theta}$ & & & & & $(0.004$ & $\begin{array}{l}88 \\
0.0328)\end{array}$ \\
\hline$\hat{\tau}$ & & & & & $(0.002$ & 20 \\
\hline AIC & & & & 76349 & & \\
\hline $\mathrm{BIC}$ & & & & 77853 & & \\
\hline $\mathrm{N}$ & & & & 7760 & & \\
\hline
\end{tabular}

Note: In the above tables (2 and 3) Est. is estimate; Std. err. Is Standard error of the estimate, Edf is empirical density function, Chi.sq. is the corresponding chi square statistic value of the edf; and finally C.I. stands for the confidence interval on the estimate.

The significance code is: $* * *$ for $0.1 \%$ level, $* *$ for $1 \%$ level, and $*$ for $5 \%$ significance level. 


\section{References:}

Alcantara, S. C., González-Carrasco, M., Montserrat, C., Viñas, F., Casas, F., \& Abreu, D. P. (2017). Peer violence in the school environment and its relationship with subjective well-being and perceived social support among children and adolescents in Northeastern Brazil. Journal of Happiness Studies, 18(5), 1507-1532.

Awartani, M., Whitman, C. V., \& Gordon, J. (2008). Developing Instruments to Capture Young People's Perceptions of how School as a Learning Environment Affects their Well-Being. European Journal of Education, 43(1), 51-70.

Blum, R. W., McNeely, C., \& Rinehart, P. M. (2002). Improving the odds: The untapped power of schools to improve the health of teens. Center for Adolescent Health and Development.

Bradshaw, J., Crous, G., Rees, G., \& Turner, N. (2017). Comparing children's experiences of schoolsbased bullying across countries. Children and Youth Services Review, 80, 171-180.

Burr, C., Taddeo, M., \& Floridi, L. (2019). The Ethics of Digital Well-Being: A Thematic Review. Science and Engineering Ethics, 1-31.

Cangas, A. J., Fínez, M. J., Morán, C., Navarro, N., \& Moldes, P. (2019). Mental Health, New Technologies, and Wellbeing for Adolescents. In Enhancing Resilience in Youth (pp. 233-243). Springer, Cham.

Cherubini, U., Luciano, E., \& Vecchiato, W. (2004). Copula methods in finance. John Wiley \& Sons.

Clayton, R. B., Leshner, G., \& Almond, A. (2015). The extended iSelf: The impact of iPhone separation on cognition, emotion, and physiology. Journal of Computer-Mediated Communication, 20(2), 119-135.

Clement, N. (2010). Student wellbeing at school: The actualization of values in education.

In International research handbook on values education and student wellbeing (pp. 37-62). Springer, Dordrecht.

Cohen, J. (2006). Social, emotional, ethical, and academic education: Creating a climate for learning, participation in democracy, and well-being. Harvard educational review, 76(2), 201-237.

Crompton, H., Burke, D., \& Gregory, K. H. (2017). The use of mobile learning in PK-12 education: A systematic review. Computers \& Education, 110, 51-63.

Dhir, A., Yossatorn, Y., Kaur, P., \& Chen, S. (2018). Online social media fatigue and psychological wellbeing - A study of compulsive use, fear of missing out, fatigue, anxiety and depression. International Journal of Information Management, 40, 141-152.

Dickson, K., Richardson, M., Kwan, I., Macdowall, W., Burchett, H., Stansfield, C., \& Thomas, J. (2019). Screen-based activities and children and young people's mental health and psychosocial wellbeing: a systematic map of reviews. London: EPPI-Centre, Social Science Research Unit, UCL Institute of Education, University College London.

Dinisman, T., \& Ben-Arieh, A. (2016). The characteristics of children's subjective well-being. Social indicators research, 126(2), 555-569.

Dinisman, T., Andresen, S., Montserrat, C., Strózik, D., \& Strózik, T. (2017). Family structure and family relationship from the child well-being perspective: Findings from comparative analysis. Children and Youth Services Review, 80, 105-115. 
Domoff, S. E., Borgen, A. L., Foley, R. P., \& Maffett, A. (2019). Excessive use of mobile devices and children's physical health. Human Behavior and Emerging Technologies, 1(2), 169-175.

Durante, F., \& Sempi, C. (2010). Copula theory: an introduction. In Copula theory and its applications (pp. 3-31). Springer, Berlin, Heidelberg.

De Leon, A. R., \& Wu, B. (2011). Copula-based regression models for a bivariate mixed discrete and continuous outcome. Statistics in Medicine, 30(2), 175-185.

Eilers, P. H., \& Marx, B. D. (1996). Flexible smoothing with B-splines and penalties. Statistical science, 89-102.

Elhai, J. D., Rozgonjuk, D., Alghraibeh, A. M., \& Yang, H. (2019). Disrupted daily activities from interruptive smartphone notifications: Relations with depression and anxiety severity and the mediating role of boredom proneness. Social Science Computer Review, 0894439319858008.

Ganzeboom, H.B.G. and D.J. Treiman (2003), "Three internationally standardised measures for comparative research on occupational status", in J.H.P. Hoffmeyer-Zlotnik and C. Wolf (eds.), Advances in Cross-National Comparison, A European Working Book for Demographic and SocioEconomic Variables, pp. 159-193, Kluwer Academic Press, New York.

Gilbert, P., \& Varadhan, R. (2016). numDeriv: Accurate numerical derivatives. r package version 2016.8-1.

Goodall, D., Ban, S., Birks, E., \& Clifton, A. (2013). New perspectives on the contribution of digital technology and social media use to improve the mental wellbeing of children and young people: A state-of-the-art review. Neonatal, Paediatric \& Child Health Nursing, 16(1), 19.

Ignatjeva, S., Bruk, Z., \& Semenovskikh, T. (2019). Reflective Component in the Structure of Children's Subjective Well-Being. Child Indicators Research, 1-26.

James, C., Davis, K., Charmaraman, L., Konrath, S., Slovak, P., Weinstein, E., \& Yarosh, L. (2017). Digital life and youth well-being, social connectedness, empathy, and narcissism. Pediatrics, 140 (Supplement 2), S71-S75.

Joe, H. (2014). Dependence modeling with copulas. Chapman and Hall/CRC.

Kangas, M. (2010). Finnish children's views on the ideal school and learning environment. Learning Environments Research, 13(3), 205-223.

Kaye-Tzadok, A., Ben-Arieh, A., \& Kosher, H. (2019). Hope, Material Resources, and Subjective Well-Being of 8-to 12-Year-Old Children in Israel. Child development, 90(2), 344-358.

Kern, M. L., Waters, L. E., Adler, A., \& White, M. A. (2015). A multidimensional approach to measuring well-being in students: Application of the PERMA framework. The journal of positive psychology, 10(3), 262-271.

Klein, N., \& Kneib, T. (2016). Simultaneous inference in structured additive conditional copula regression models: a unifying Bayesian approach. Statistics and Computing, 26(4), 841-860.

Kolev, N., \& Paiva, D. (2009). Copula-based regression models: A survey. Journal of statistical planning and inference, 139(11), 3847-3856.

Lau, M. K., Gordon, D., Zhang, M. F., \& Bradshaw, J. (2019). Children's and adults' perceptions of child necessities in Hong Kong. Social Policy \& Administration, 53(6), 835-853. 
Laurence, J. (2019). Community disadvantage, inequalities in adolescent subjective well-being, and local social relations: The role of positive and negative social interactions. Social Science \& Medicine, 237, 112442.

Lee, B. J., \& Yoo, M. S. (2015). Family, school, and community correlates of children's subjective well-being: An international comparative study. Child Indicators Research, 8(1), 151-175.

Loebach, J., Tilleczek, K., Chaisson, B., \& Sharp, B. (2019). Keyboard warriors? Visualising technology and well-being with, for and by indigenous youth through digital stories. Visual Studies, 34(3), 281-297.

Loid, K., Täht, K., \& Rozgonjuk, D. (2020). Do pop-up notifications regarding smartphone use decrease screen time, phone checking behavior, and self-reported problematic smartphone use? evidence from a two-month experimental study. Computers in Human Behavior, 102, 22-30.

Main, G. (2019). Money matters: A nuanced approach to understanding the relationship between household income and child subjective well-being. Child Indicators Research, 12(4), 1125-1145.

Marra G. and Radice R. (2017), SemiParBIVProbit: Semiparametric Copula Bivariate Probit Modelling. $R$ package version 3.8.1.

Marino, C., Gini, G., Vieno, A., \& Spada, M. M. (2018). The associations between problematic Facebook use, psychological distress and well-being among adolescents and young adults: A systematic review and meta-analysis. Journal of Affective Disorders, 226, 274-281.

Migliorini, L., Tassara, T., \& Rania, N. (2019). A Study of Subjective Well-Being and Life Satisfaction in Italy: how are Children doing at 8 years of Age?. Child Indicators Research, 12(1), 4969.

Miranda, R., Oriol, X., Amutio, A., \& Ortúzar, H. (2019). Adolescent bullying victimization and life satisfaction: Can family and school adult support figures mitigate this effect?. Revista de Psicodidáctica (English ed.), 24(1), 39-45.

Moore, A., \& Lynch, H. (2018). Understanding a child's conceptualisation of well-being through an exploration of happiness: The centrality of play, people and place. Journal of Occupational Science, 25(1), 124-141.

Muscarà, M., Pace, U., Passanisi, A., D’Urso, G., \& Zappulla, C. (2018). The transition from middle school to high school: the mediating role of perceived peer support in the relationship between family functioning and school satisfaction. Journal of Child and Family Studies, 27(8), 2690-2698.

Navarro, R., Lee, S. H., Jiménez, A., \& Cañamares, C. (2019). Cross-Cultural children's Subjective Perceptions of Well-Being: Insights from Focus Group Discussions with Children Aged under 9 years in Spain, South Korea and Mexico. Child Indicators Research, 12(1), 115-140.

Newland, L. A., Mourlam, D., \& Strouse, G. (2018). A phenomenological exploration of the role of digital technology and media in children's subjective well-being. Child Indicators Research, 11(5), 1563-1583.

OECD (2017), PISA 2015 Technical Report: Chapter 16 - Procedures and Construct Validation of Context Questionnaire Data, Organization for Economic Co-operation and Development, Paris, France. Retrieved on 29 December 2019 from. URL:http://www.oecd.org/pisa/sitedocument/PISA-2015-technical-report-final.pdf

OECD (2019), Programme for International Student Assessment (PISA) 2018 Database: Student Questionnaire data file, Organization for Economic Co-operation and Development, Paris, France. Retrieved on 10 December 2019 from URL: http://www.oecd.org/pisa/data/2018database/ 
Orben, A., \& Przybylski, A. K. (2019). Screens, teens, and psychological well-being: Evidence from three time-use-diary studies. Psychological science, 30(5), 682-696.

Parry, D. A., le Roux, D. B., \& Bantjes, J. R. (2020). Testing the feasibility of a media multitasking self-regulation intervention for students: Behaviour change, attention, and self-perception. Computers in Human Behavior, 104, 106182.

Poulou, M., \& Norwich, B. (2019). Psychological needs, mixed self-perceptions, well-being and emotional, and behavioral difficulties: adolescent students' perceptions. European Journal of Psychology of Education, 1-19.

Radice, R., Marra, G., \& Wojtyś, M. (2016). Copula regression spline models for binary outcomes. Statistics and Computing, 26(5), 981-995.

Rodgers, R. F., Slater, A., Gordon, C. S., McLean, S. A., Jarman, H. K., \& Paxton, S. J. (2020). A Biopsychosocial Model of Social Media Use and Body Image Concerns, Disordered Eating, and Muscle-Building Behaviors among Adolescent Girls and Boys. Journal of Youth and Adolescence, 111.

Rose, T., Joe, S., Williams, A., Harris, R., Betz, G., \& Stewart-Brown, S. (2017). Measuring mental wellbeing among adolescents: a systematic review of instruments. Journal of Child and Family Studies, 26(9), 2349-2362.

Rue, H., \& Held, L. (2005). Gaussian Markov random fields: theory and applications. Chapman and Hall/CRC.

Saunders, P., \& Brown, J. E. (2019). Child Poverty, Deprivation and Well-Being: Evidence for Australia. Child Indicators Research, 1-18.

Scales, P. C., Benson, P. L., Oesterle, S., Hill, K. G., Hawkins, J. D., \& Pashak, T. J. (2016). The dimensions of successful young adult development: A conceptual and measurement framework. Applied Developmental Science, 20(3), 150-174.

Schütz, F. F., Bedin, L. M., \& Sarriera, J. C. (2019). Subjective Well-Being of Brazilian children from different family settings. Applied Research in Quality of Life, 14(3), 737-750.

Sha, P., Sariyska, R., Riedl, R., Lachmann, B., \& Montag, C. (2019). Linking internet communication and smartphone use disorder by taking a closer look at the Facebook and WhatsApp applications. Addictive behaviors reports, 9, 100148.

Sindermann, C., Elhai, J. D., \& Montag, C. (2020). Predicting Tendencies towards the Disordered Use of Facebook's Social Media Platforms: On the role of Personality, Impulsivity, and Social Anxiety. Psychiatry Research, 112793.

Sklar, A. (1973). Random variables, joint distribution functions, and copulas. Kybernetika, 9(6), 449460.

Soutter, A. K., O'Steen, B., \& Gilmore, A. (2012). Wellbeing in the New Zealand curriculum. Journal of Curriculum Studies, 44(1), 111-142.

Stasinopoulos, D. M., \& Rigby, R. A. (2007). Generalized additive models for location scale and shape (GAMLSS) in R. Journal of Statistical Software, 23(7), 1-46.

Strelhow, M. R. W., Sarriera, J. C., \& Casas, F. (2019). Evaluation of Well-Being in Adolescence: Proposal of an Integrative Model with Hedonic and Eudemonic Aspects. Child Indicators Research, 114. 
Thomson, E., \& McLanahan, S. S. (2012). Reflections on "Family structure and child well-being: Economic resources vs. parental socialization”. Social Forces, 91(1), 45-53.

Tomyn, A. J., \& Cummins, R. A. (2011). The subjective wellbeing of high-school students: Validating the personal wellbeing index-school children. Social Indicators Research, 101(3), 405-418.

Trivedi, P. K., \& Zimmer, D. M. (2007). Copula modeling: an introduction for practitioners. Foundations and Trends ${ }^{\circledR}$ in Econometrics, 1(1), 1-111.

Thapa, A., Cohen, J., Guffey, S., \& Higgins-D’Alessandro, A. (2013). A review of school climate research. Review of educational research, 83(3), 357-385.

Tiliouine, H., \& Meziane, M. (2017). The history of well-being in the Middle East and North Africa (MENA). In The Pursuit of Human Well-Being (pp. 523-563). Springer, Cham.

United Nations (2015). Transforming our world: the 2030 Agenda for Sustainable Development, The United Nations Department of Economic and Social Affairs, Retrieved on 02 December 2019 from. URL: https://sustainabledevelopment.un.org/post2015/transformingourworld/publication

Vannucci, A., \& Ohannessian, C. M. (2019). Social media use subgroups differentially predict psychosocial well-being during early adolescence. Journal of youth and adolescence, 48(8), 14691493.

Varela, J. J., Savahl, S., Adams, S., \& Reyes, F. (2019). Examining the relationship among bullying, school climate and adolescent well-being in Chile and South Africa: a cross cultural comparison. Child Indicators Research, 1-20.

Vatter, T., \& Chavez-Demoulin, V. (2015). Generalized additive models for conditional dependence structures. Journal of Multivariate Analysis, 141, 147-167.

Wang, M. T., \& Degol, J. L. (2016). School climate: A review of the construct, measurement, and impact on student outcomes. Educational Psychology Review, 28(2), 315-352.

Warm, T. A. (1989), weighted likelihood estimation of ability in item response theory, Psychometrika, Vol. 54, pp. 427-450.

Wood, S. N. (2017). Generalized additive models: an introduction with R. Chapman and Hall/CRC.

Wojtyś, M., Marra, G., \& Radice, R. (2018). Copula based generalized additive models for location, scale and shape with non-random sample selection. Computational Statistics \& Data Analysis, 127, 114.

Xin, M., Xing, J., Pengfei, W., Houru, L., Mengcheng, W., \& Hong, Z. (2018). Online activities, prevalence of Internet addiction and risk factors related to family and school among adolescents in China. Addictive Behaviors Reports, 7, 14-18.

Yee, T. W. (2015). Vector generalized linear and additive models: with an implementation in $R$. Springer.

Zeng, G., Hou, H., \& Peng, K. (2016). Effect of growth mindset on school engagement and psychological well-being of Chinese primary and middle school students: The mediating role of resilience. Frontiers in psychology, 7, 1873. 